\title{
Information Technology Planning Framework for Japanese General Contractors
}

\author{
by \\ Shunsuke Tanaka \\ Bachelor of Engineering \\ The University of Tokyo, 1992
}

Submitted to the Department of Civil and Environmental Engineering in Partial Fulfillment of the Requirements for the Degree of Master of Science in Civil and Environmental Engineering

ENG

at the

\section{Massachusetts Institute of Technology}

June 2000

(C) 2000 Shunsuke Tanaka, All rights reserved

MASSACHUSETTS INSTITUTE

OF TECHNOLOGY

MAY 302000

LIBRARIES

The author hereby grants to MIT permission to reproduce and to distribute publicly paper and electronic copies of this thesis document in whole or in part.

Signature of Author

Department of Civil and Environmental Engineering

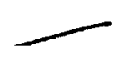

May 5, 2000

Certified by

Fe(iiosky Peña-Mora

Associate Professor of Civil and Environmental Engineering

Thesis Supervisor

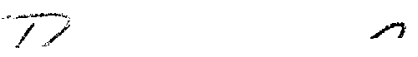

Accepted by.

Daniele Veneziano

Chairman, Departmental Committee on Graduate Studies 


\title{
Information Technology Planning Framework for Japanese General Contractors
}

by

\author{
Shunsuke Tanaka
}

Submitted to the Department of Civil and Environmental Engineering on May 5, 2000 in Partial Fulfillment of the Requirements for the Degree of Master of Science in Civil and Environmental Engineering

\begin{abstract}
New information technology (IT) developments continue to have a significant impact on the Architectural/Engineering/Construction (A/E/C) industry. However, the issue of whether $\mathrm{A} / \mathrm{E} / \mathrm{C}$ organizations are receiving adequate returns from their IT investments remains an important managerial concern. Recently, Peña-Mora, Vadhavkar, Perkins, and Weber introduced a strategic IT planning framework for construction companies, which is composed of four steps: environmental scan, internal scrutiny, IT diffusion analysis, and IT investment modeling. It analyzes the external and internal IT conditions of a firm, defines the diffusion stage of IT in a firm and finally, evaluates the effects of investments on IT projects.

This thesis examines the validity of applying the above-mentioned framework to the Japanese construction industry and in greater detail to Japanese general contractors, using the Kajima Corporation, one of the largest general contractors in Japan, as a case study. The Kajima Corporation is currently developing an IT project called Linkage of Information for a New Construction System (henceforth LINCS). This synthetic information network system connects design with construction work. By using the strategic IT planning framework, I evaluate LINCS in terms of its strategy and the effects of Kajima's investment on this system.
\end{abstract}

Thesis Supervisor: Feniosky Peña-Mora

Title: Associate Professor of Civil and Environmental Engineering 


\section{Acknowledgments}

It goes without saying that most of the students cannot accomplish their graduate study by themselves. I needed a lot of help from a lot of people.

I would like to express my deep gratitude to all the following:

To my academic and thesis advisor, Professor Feniosky Peña-Mora, for giving me constant guidance and keeping my research on the right track. His energy is enormous and his amicable attitude to everyone is admirable; these traits will be the goals for my future life;

To all the members at the Intelligent Engineering Systems Laboratory (IESL) for giving me valuable ideas and advice and lots of fun, and to Joan McCusker, secretary of IESL, for arranging an office space for me;

To my colleague, Takashi Kyogoku, for giving me financial knowledge and valuable materials;

To my interviewees at Kajima - Yukio Endo, Harumi Sakai and Fumie Yamane - for sparing their time and giving me invaluable information for my research, and to my fellow workers at Kajima - Yasuko Kato, Manabu Masuda and Kenichi Takahashi - for sending me helpful materials;

To Betsy Fox and other staff at the Writing and Communication Center, for their kind and careful work of polishing my English; and

To Kajima Corporation, for giving me the opportunity to study at MIT. There is no way I can measure all that I obtained from my two years at MIT.

Last, I dedicate this thesis to my loving wife, Yoshie and the baby inside her. Without Yoshie's incessant support, I would not have completed this work.

Cambridge, Massachusetts

Shunsuke Tanaka

June 2000 


\section{Table of Contents}

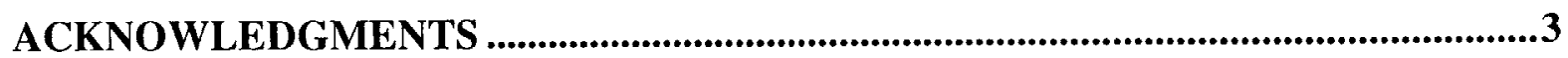

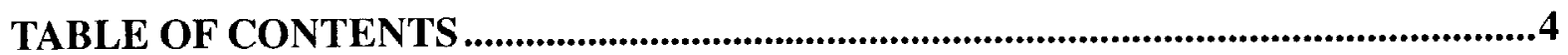

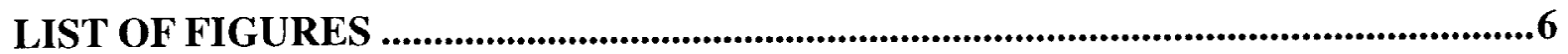

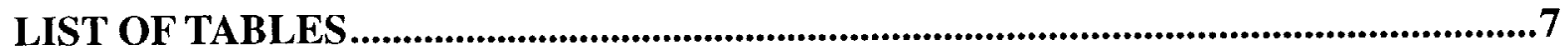

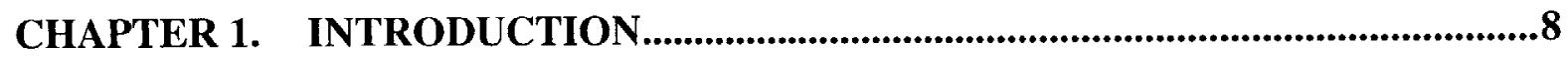

$\begin{array}{llr}\text { 1.1. } & \text { Research Objectives } & 8\end{array}$

$\begin{array}{ll}\text { 1.2. General Approach } & 9\end{array}$

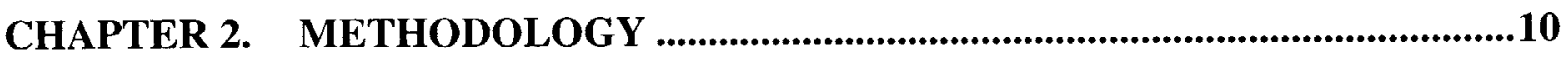

$\begin{array}{ll}\text { 2.1. Overview of the IT Planning Framework } & 10\end{array}$

2.2. Four Steps of the IT Planning Framework 12

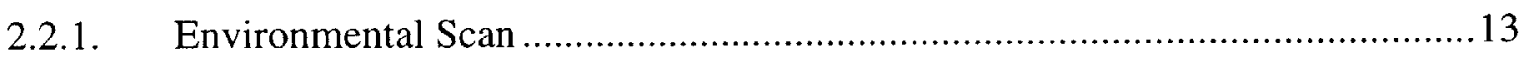

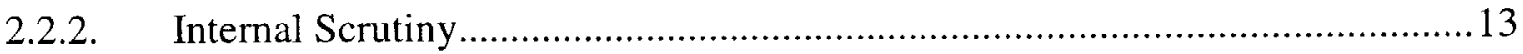

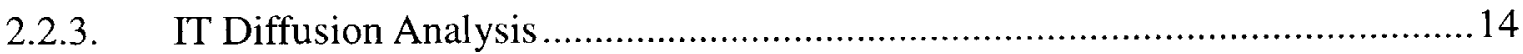

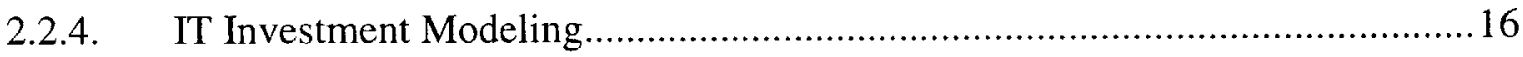

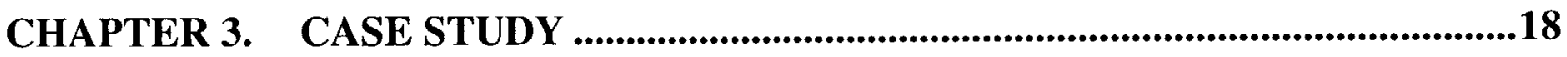

3.1. Environmental Scan $\quad 18$

3.1.1. Characteristics of Japanese General Contractors ..................................... 19

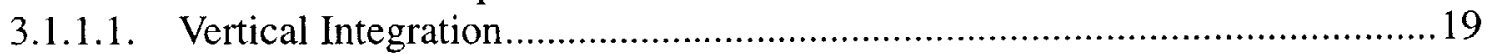

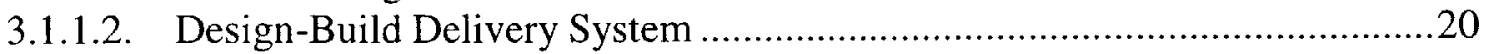

3.1.2. Economic Environment in the Japanese Construction Industry ....................21

3.1.3. The Position of IT in the Japanese Construction Industry ...........................22

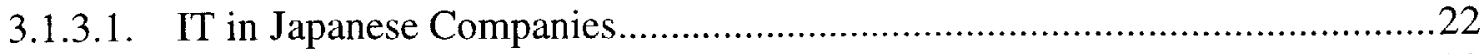

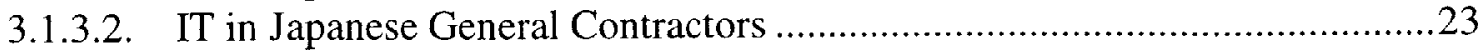


3.2. Internal Scrutiny 29

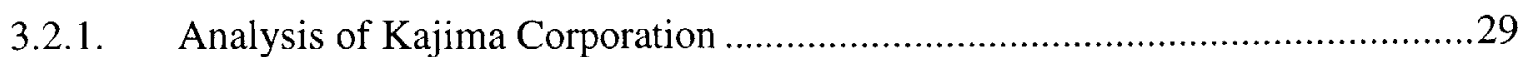

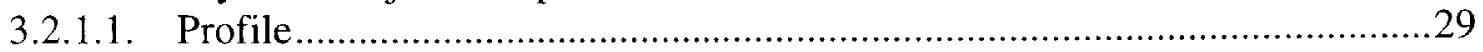

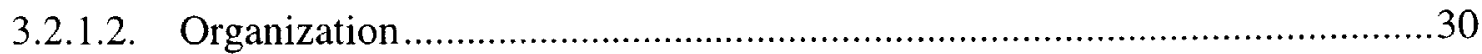

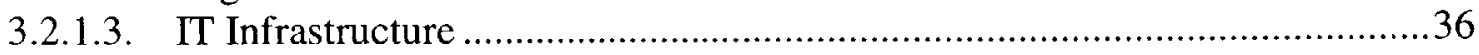

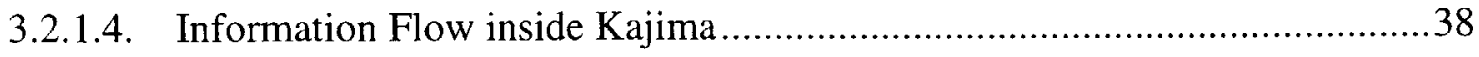

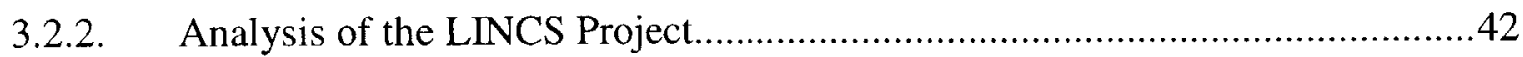

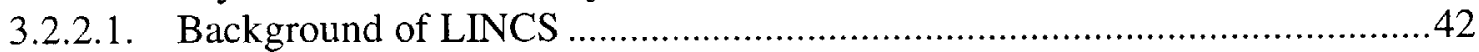

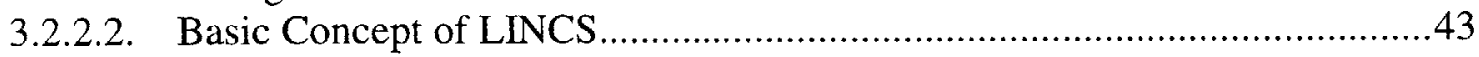

3.2.2.3. Project Organization of LINCS ............................................................44

3.2.2.4. Configuration of LINCS ....................................................................4

$\begin{array}{lr}\text { 3.3. IT Diffusion Analysis } & 47\end{array}$

3.3.1. Diffusion of the Level of Informatization..................................................47

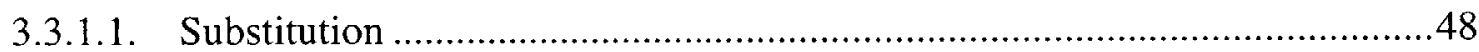

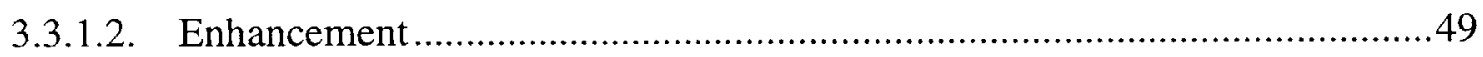

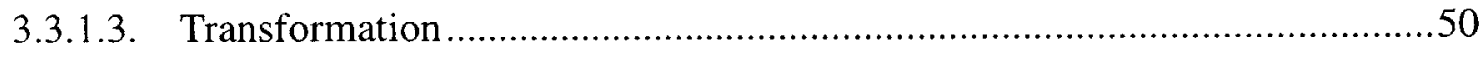

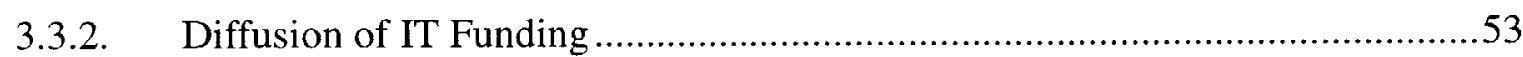

3.3.3. IT Diffusion Modeling ..............................................................................5

3.4. IT Investment Modeling $\quad 58$

3.4.1. Assessing the Business Value of IT ...........................................................58

3.4.1.1. A Process-Oriented Framework …….....................................................58

3.4.1.2. Process-Oriented IT Business Value Matrix ...............................................59

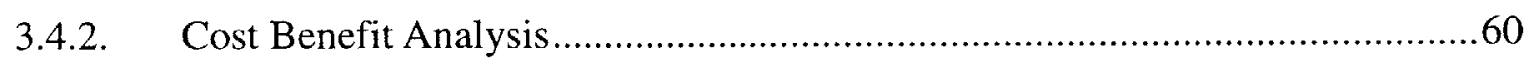

3.4.2.1. Classification of Investments and Benefits ..............................................60

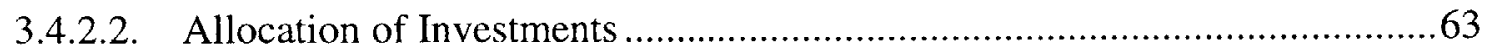

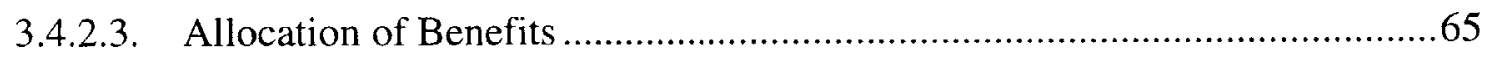

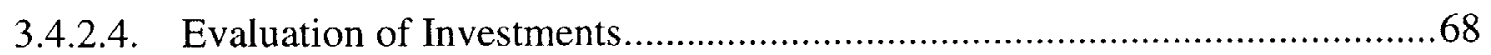

CHAPTER 4. CONCLUSION ............................................................................................70

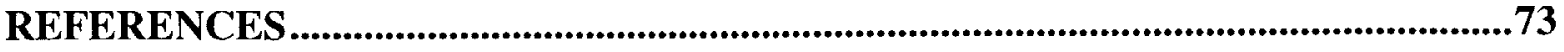




\section{List of Figures}

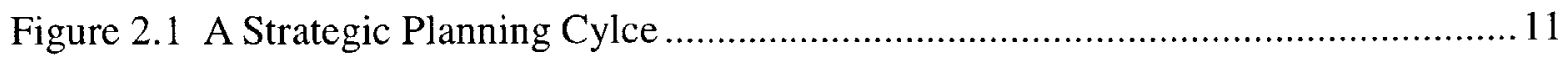

Figure 2.2 Flow of the IT Strategic Planning Framework ...............................................12

Figure 2.3 IT Diffusion Modeling: Level of Informatization ..........................................15

Figure 2.4 IT Diffusion Modeling: IT Funding............................................................ 16

Figure 3.1 Typical Construction Project Workflow and Related Database.........................25

Figure 3.2 Vertical Integration of Kajima ..................................................................... 31

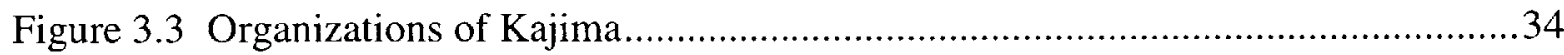

Figure 3.4 Organizations of Kajima and Their Relationship with the Construction

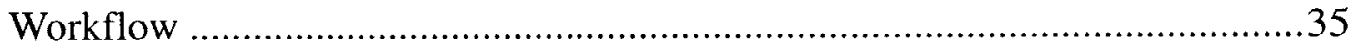

Figure 3.5 Three Pillars of Information Processing System in Kajima ...............................36

Figure 3.6 Generic Overview of Intra-firm Information Flow ..........................................39

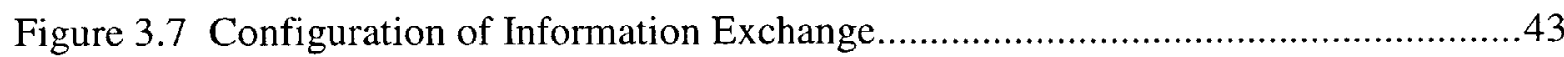

Figure 3.8 The Organization of the Development of LINCS .............................................44

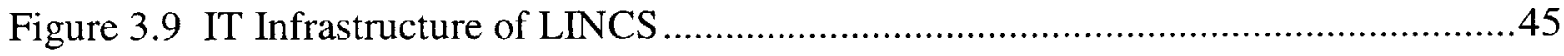

Figure 3.10 Relationship of LINCS with the Typical Workflow of Construction Projects .46

Figure 3.11 Adoption Percentage of CAD/DBCAD/LINCS in the Construction Projects in

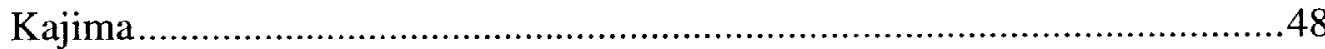

Figure 3.12 The Fundamental Process of Structural Design.............................................50

Figure 3.13 The Change of Drawing Process in the Structural Design before/after the Introduction of DBCAD........................................................................

Figure 3.14 Changes of Structural Design Schedule with/without IT ..............................52

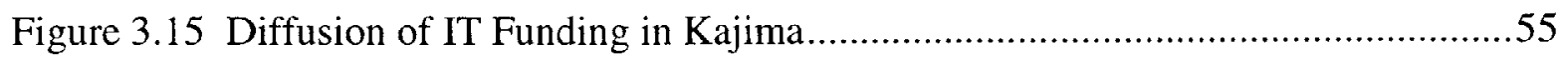

Figure 3.16 System Dynamics Model for IT Diffusion .....................................................57

Figure 3.17 IT Program Inputs and Outputs .................................................................61 


\section{List of Tables}

Table 3.1 Comparison of IT Framework between Western and Japanese.......................24

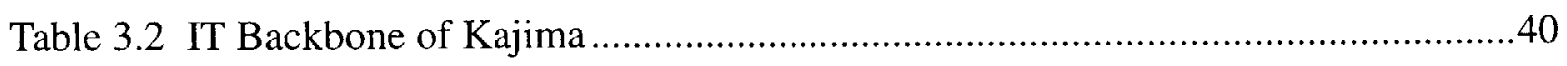

Table 3.3 Kajima's Investments in R\&D and Plant and Equipment ..............................54

Table 3.4 Process-oriented IT Business Value Matrix ............................................60

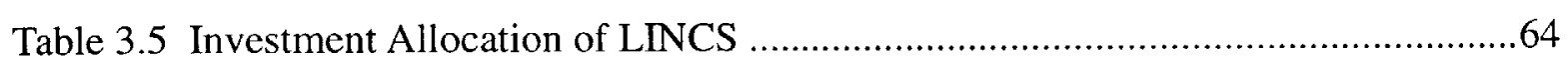

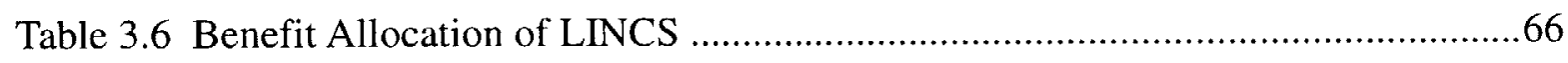

Table 3.7 Inequality in Investment and Benefit Allocation of LINCS ..........................69 


\section{Chapter 1. Introduction}

\subsection{Research Objectives}

The importance of information technology (IT) in the Architectural, Construction, and Engineering $(\mathrm{A} / \mathrm{C} / \mathrm{E})$ industry has grown exponentially over the past several years. Various IT applications, such as CAD packages, scheduling and contract management software, document management systems and Internet applications, have improved service quality and productivity of the $\mathrm{A} / \mathrm{C} / \mathrm{E}$ industry. Hence, investments in IT have become a dominant part of capital budgets of many large-scale $\mathrm{A} / \mathrm{C} / \mathrm{E}$ projects.

On the other hand, as IT becomes a dominant part of capital budgets, management of IT investment processes becomes an increasingly critical issue for senior management of $\mathrm{A} / \mathrm{E} / \mathrm{C}$ companies. To be concrete, senior management of $\mathrm{A} / \mathrm{E} / \mathrm{C}$ firms is confronted with the following difficult questions:

- How should IT investments be designed to ensure alignment with overall objectives and strategy of a company?

- How should these investments be justified?

- How can the value of these IT investments be measured? 
- How can the value of IT investments be qualified when the benefits accrue to more than one participating party?

Previous research focused on the IT investments in large-scale A/E/C projects (Peña-Mora, et al., 1999) and small manufacturing companies (Weber, 1997). In this thesis, I focus on the IT investments in the Japanese construction industry, especially in Japanese general contractors.

\subsection{General Approach}

Answering these questions mentioned in the previous section requires a paradigm shift from the current project management approach to an investment management approach (Peña-Mora, et al., 1999). The important factors of the investment management approach are periodic valuation, monitoring, and evaluation of investment programs over the project's life span. The IT diffusion based strategic planning framework is one type of investment management approach particularly intended for the $\mathrm{A} / \mathrm{E} / \mathrm{C}$ industry. It was first introduced by Peña-Mora and Weber (1997), and it analyzes the external and internal IT conditions of a firm, defines the diffusion stage of IT in a firm and, finally, evaluates the effects of investments on IT projects. In this thesis, following this framework, I analyze large-scale Japanese general contractors because most of the large construction companies in Japan are general contractors.

In the case study, I evaluate the IT strategy of Kajima Corporation, one of the top five general contractors in Japan. Kajima is currently developing an IT project called LINCS. LINCS is a synthetic information network system which connects design and construction work. Using the IT strategic planning framework reveals the advantages and disadvantages of the LINCS project. Last, I evaluate LINCS in terms of its strategy and the effect of Kajima's investment on this system. 


\section{Chapter 2. Methodology}

This chapter presents a method to analyze and evaluate an IT strategy or an IT program in a company. The method, designed by Peña-Mora, Vadhavkar, Perkins, and Weber (1999), is called the strategic IT planning framework and is based on the IT diffusion model for the economic sector in a region. The framework consists of four steps: (1) environmental scan, (2) internal scrutiny, (3) IT diffusion analysis, and (4) IT investment modeling. In the following sections, the detail of each step will be discussed.

\subsection{Overview of the IT Planning Framework}

Prior to the introduction of the IT diffusion-based strategic planning framework, several valuation frameworks had been proposed in the literature (Mooney et al., 1996; Brynjolfsson and Hitt, 1996) to estimate the value of IT for a firm. Those prior research efforts suggested that second-order effects, such as the efficiency variability of ownercontractor relationships, have to be taken into account for a correct assessment of IT value. Although these effects are typical in $\mathrm{A} / \mathrm{E} / \mathrm{C}$ projects, they complicate the necessary analysis.

The strategic IT planning approach formulated here was first introduced by Peña-Mora, Vadhavkar, Perkins, and Weber (1999). It is based on their prior research (Weber and Peña- 
Mora, 1997) on a generic IT diffusion model for the economic sector in a region. This framework clarifies what role IT can play and where it can add value compared with other more traditional production factors and provides a unifying architecture for dynamically analyzing field data and the associated IT investment modeling.

In constructing a strategic planning framework, it is important to consider that the feedback nature of strategy and strategic planning, due to the uncertainty involved in the observation of system parameters and externalities, as well as the limited planning horizon. Hence, strategy has to dynamically adjust and take induced organizational changes as well as changes in boundary conditions of the business model into account. Figure 2.1 illustrates a resulting strategic planning cycle that feeds back into the performance objectives and eventually strategic goals it tries to accomplish.

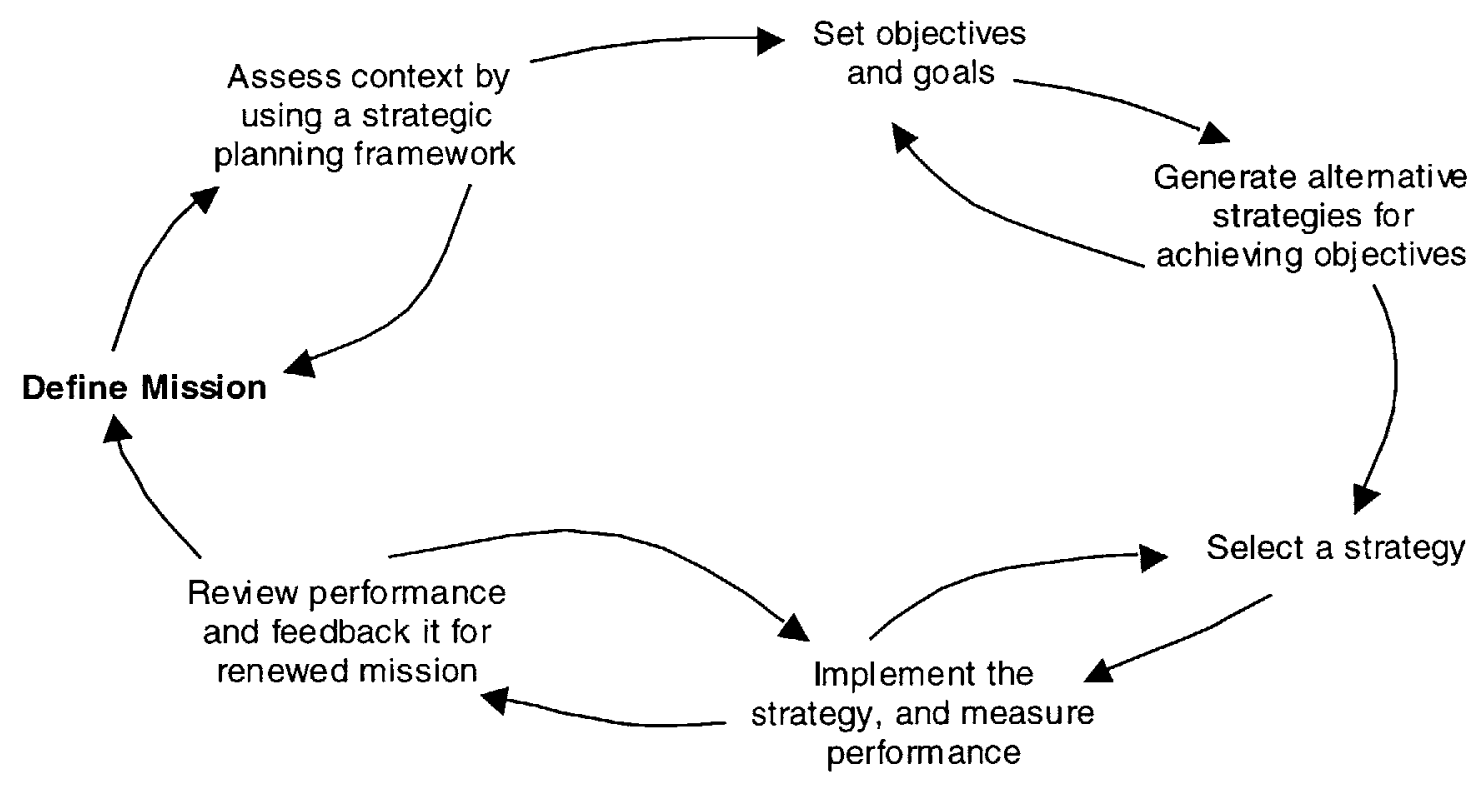

Figure 2.1 A Strategic Planning Cylce (adopted from Weber, 1997) 


\subsection{Four Steps of the IT Planning Framework}

As mentioned in the previous section, the essential steps in the strategic planning framework are: (1) environmental scan, (2) internal scrutiny, (3) IT diffusion analysis, and (4) IT investment modeling. Figure 2.2 illustrates the flow of this framework. Following these steps, we eventually formulate the strategic IT planning framework for a company. The details of each step are discussed in the following sections.

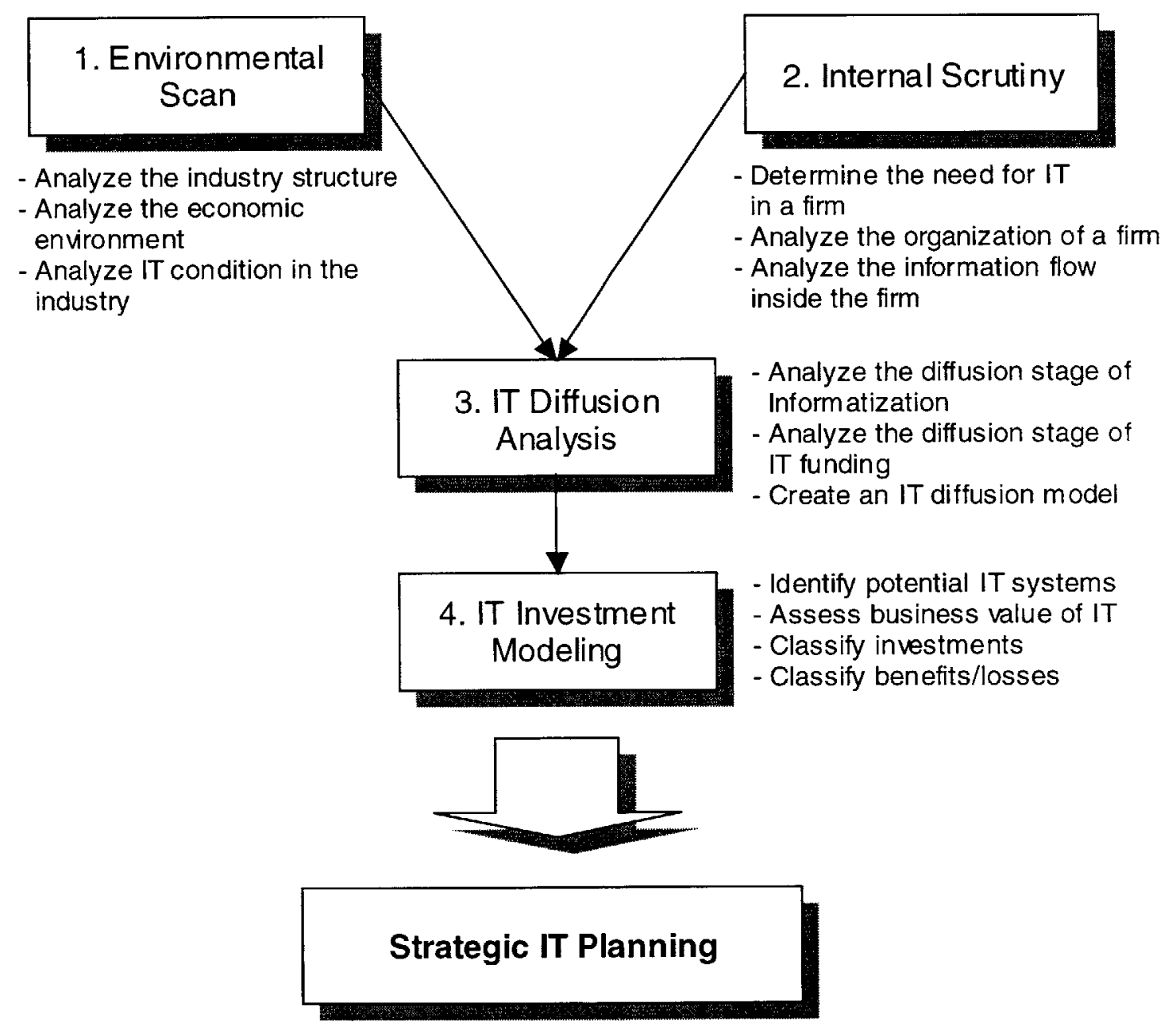

Figure 2.2 Flow of the IT Strategic Planning Framework (adapted from Weber, 1997) 


\subsubsection{Environmental Scan}

The first step in the framework is to understand the business of the $\mathrm{A} / \mathrm{E} / \mathrm{C}$ project as well as the dynamics of the overall economic environment in which the IT project operates. This environmental scan yields the boundary conditions for the strategy of the project, and has to be followed up by a thorough internal scrutiny at the intra-project level and the different functional units of the project. Given these two elements, one can identify the strategic thrusts and possible performance measures for the projects. The actual processes of this step are as follows:

- Analysis of the characteristics and structure of the industry in which a firm involves,

- Analysis of the economic environment of the industry, and

- Analysis of the condition of IT in the industry.

\subsubsection{Internal Scrutiny}

The second step in the development of a strategic plan is an analysis of the relevant processes and functions within a firm. The strategic thrusts and performance measures developed in the first step are used to create "guiding benchmarks" for continuous monitoring. More specifically, it is important to identify the intra-project flows of control and information within or across functions and processes. Subsequently, intra-project networks as established in strategic alliances or in contractor-owner relationships need to be considered. The actual processes of this step are as follows:

- Determination of IT needs in a firm,

- Analysis of the firm's organization and value-creating processes, and

- Analysis of the information flow inside a firm. 


\subsubsection{IT Diffusion Analysis}

The third step of the IT planning framework is IT diffusion analysis; it consists of the identification of the IT diffusion phase and the modeling of the IT diffusion within a company. In addition, two types of IT diffusion exist in implementing IT in a firm: diffusion of the level of informatization and diffusion of IT funding.

Before presenting the details of IT diffusion analysis, we have to define the IT diffusion first. Weber and Peña-Mora (1997) pointed out, when an investment in IT is made, that there is a time lag before that technology is adopted throughout the project and its full potential is harnessed. This process of adoption is termed diffusion. Three main phases of IT diffusion have been identified (Hannah et al., 1995) as follows:

1. "Substitution" of existing technologies,

2. "Enhancement" of processes, and

3. "Transformation" of organization and strategy

During the substitution phase, IT performs the existing processes that were usually done by human power. The most typical example of this substitution is that CAD software has replaced the human's handwriting work. Automated tasks, decreased transmission time, and improved efficiency are the returns obtained in this phase. During the enhancement phase, IT realizes more efficient processes in the firm's workflow that improve quality or productivity. One example of this enhancement is that the automated monitoring system of inventory which has improved the accuracy and speed of inventory management tasks. During the transformation phase, IT becomes the major part of the company's strategy and alters the structure of the value-chain in a company. The creation of a web-centric integrated field office where the contractor, designer, and owner representative work together is classified in an example of transformation. In this case, all the project participants could work collaboratively sharing the identical data that is collected once and 
reused for all the different tasks for each participant, with the definite understanding that the data are not for a single party but for all the project participants.

The actual processes of this step are as follows: The first task in the IT diffusion analysis is to identify where in the IT diffusion stage a firm is. As I mentioned in the beginning of this section, two types of IT diffusion, i.e. level of informatization and IT funding, should be analyzed. Level of informatization means the percentage of work that uses IT in the company's value-creating processes. As an IT program progresses, the level of informatization in a firm rises. The diffusion pattern of the level of informatization describes the stepwise advancement as shown in Figure 2.3. On the contrary, the diffusion pattern of the IT funding closely follows the boom/bust dynamics shown in Figure 2.4 (Peña-Mora, et al., 1999). These identifications of the diffusion stage are important to plan any IT investment correctly in a firm.

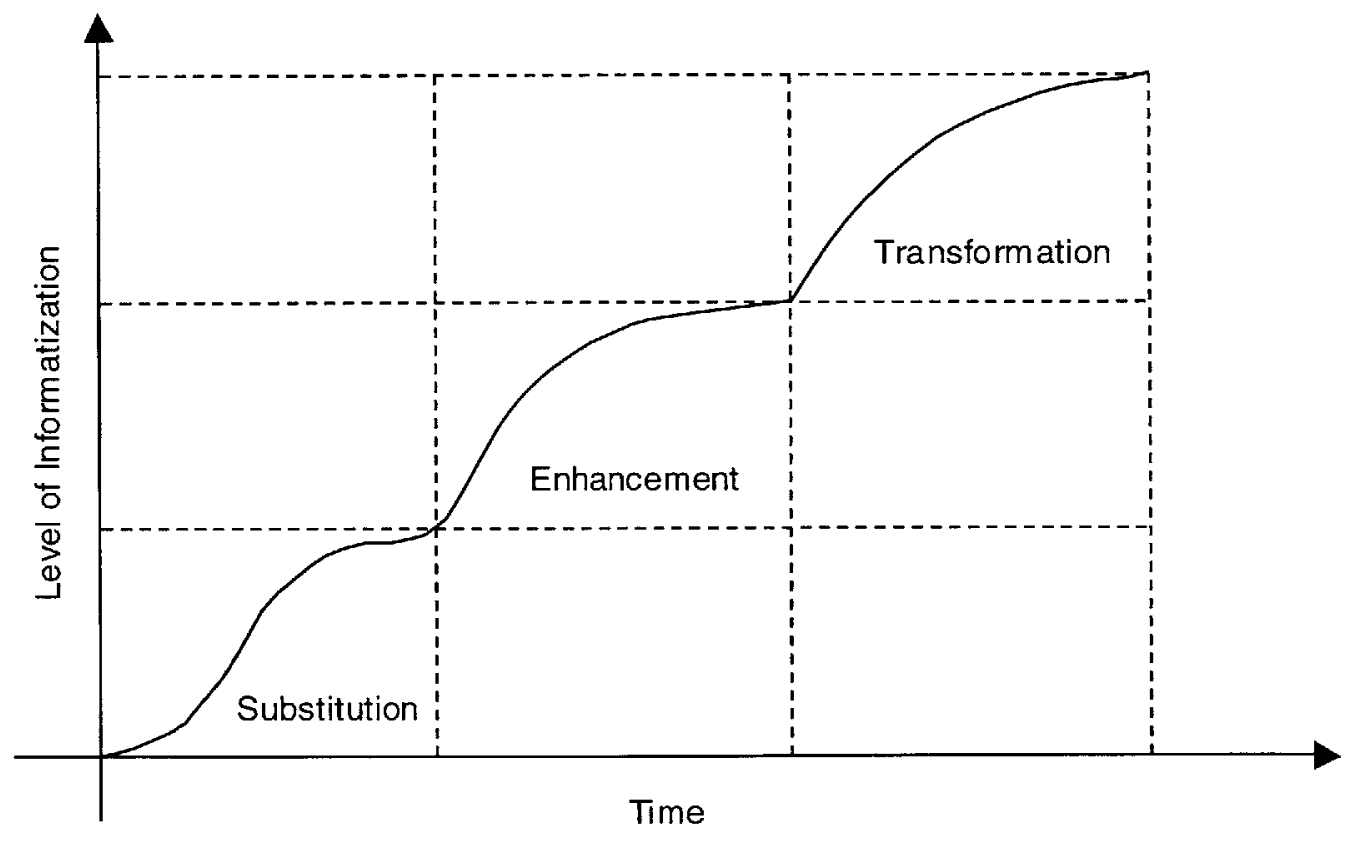

Figure 2.3 IT Diffusion Modeling: Level of Informatization (adopted from Weber and Peña-Mora, 1997) 


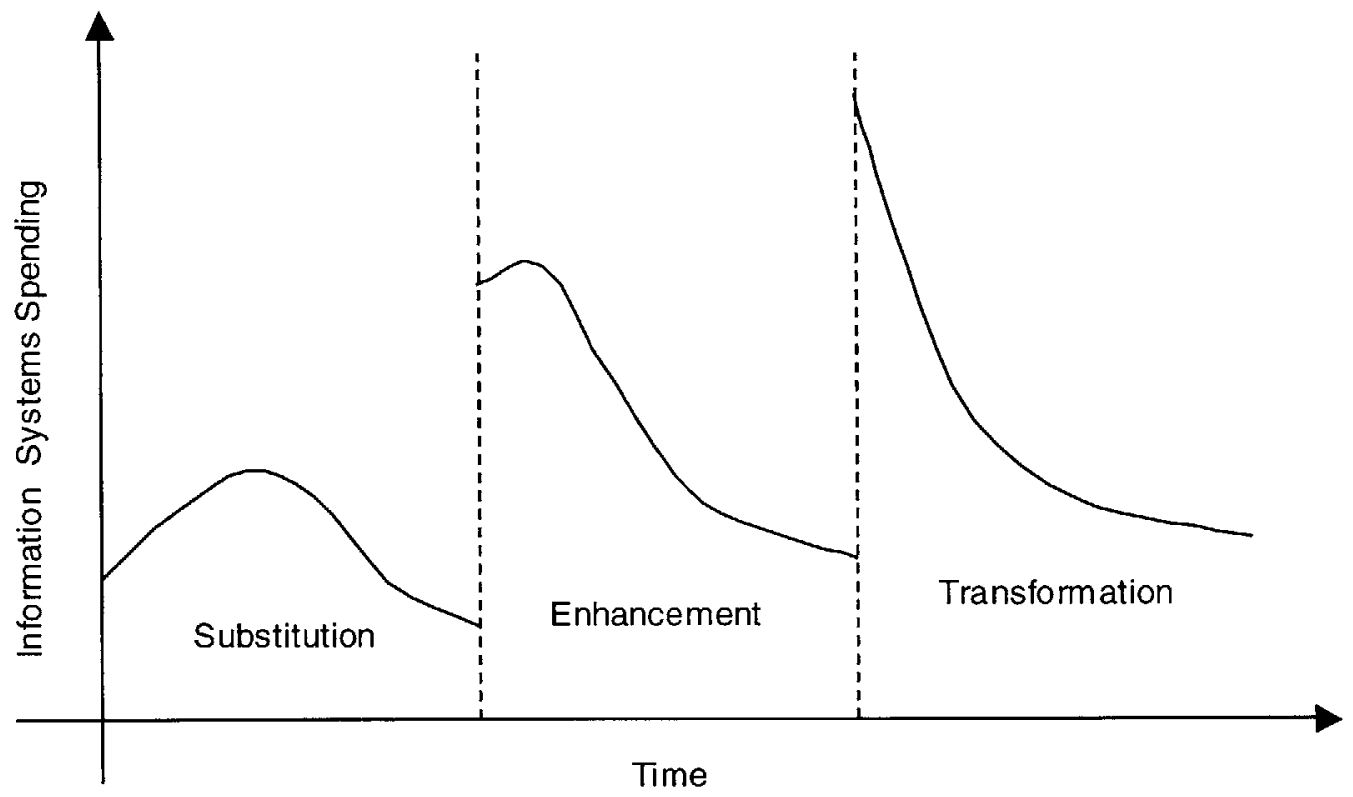

Figure 2.4 IT Diffusion Modeling: IT Funding (adopted from Weber and PeñaMora, 1997)

The second task in the IT diffusion analysis is to create a model of the IT diffusion in a firm. Weber (1997) proposed a simple causal loop model for IT diffusion at the level of a firm. This model is driven by expenditure in IT, which results in IT infrastructure. In the presence of a more sophisticated IT infrastructure the demand for IT can be expected to rise, which then increases the level of informatization. Although this causal loop diagram provides a good understanding of causal relationship, it is generally not appropriate for simulation or optimization purposes, since it does not include quantitative elements or the concept of time. We need to add state valuables as stocks and their time-derivatives as flows to visualize the dynamic mechanism of the IT diffusion.

\subsubsection{IT Investment Modeling}

The last step in the development of the strategic planning consists of developing an IT investment model that can then be integrated into the overall planning framework to devise 
the generic dynamic strategic plan. In particular, the following questions have to be considered:

- What are the current plans in terms of internal work and external information sharing?

- What are the different levels of information sharing at present (Fax paradigm, information repositories, or interactivity)?

- Which groups of information (financial, engineering/design, managerial, and documents) are likely to be shared, and which of those are the first to be made accessible?

- How do we define the information to be shared on a step-by-step progression between various project participants?

To answer these questions, the process of constructing an IT investment model can be broken down into three main processes (Peña-Mora et al., 1999): (1) System identification of potential IT applications; (2) Economic justification of each application by forecasting the return of investments; and (3) Recommendations of IT projects involving the combination of economic justifications with business logic.

In the case study presented in the following chapter, I first identify the values of the LINCS system, and second, evaluate the validity of Kajima's investment in the LINCS project by executing the cost-benefit analysis. 


\section{Chapter 3. Case Study}

This chapter presents a case study of a Japanese general contractor, Kajima Corporation, one of the largest general contractors in Japan. Kajima Corporation is currently developing an IT project called Linkage of Information for a New Construction System (henceforth LINCS). LINCS is a synthetic information network system which connects design and construction work. By using the strategic IT planning framework presented in Chapter 2, I evaluate LINCS in terms of its strategy and the effects of Kajima's investment on this project.

\subsection{Environmental Scan}

This section presents the first step of the IT planning framework: environmental scan. The first half of this environmental scan is a macroscopic survey: the analysis of the characteristics of the Japanese construction industry, especially of the general contractors, and the analysis of the economic environment of the Japanese construction industry.

However, it is not sufficient to concentrate the environmental scan at the macroscopic level of the construction industry alone (Peña-Mora et al., 1999). Following this idea, the second half is a microscopic survey: the analysis of the position of IT in the Japanese companies and the potential for adopting IT to the Japanese construction industry. 


\subsubsection{Characteristics of Japanese General Contractors}

Historically, the Japanese construction market has been traditionally classified into the construction and civil engineering fields. However, most large-scale general contractors in Japan operate in both fields, although their business may be biased more toward one or the other. The most striking characteristics of Japanese general contractors are vertically integrated market domain and the design-build delivery system. The details of these characteristics are discussed below.

\subsubsection{Vertical Integration}

Porter pointed out that a company which handles many or all of the value-adding steps in the construction processes can be called vertically integrated (Porter, 1985). The Japanese construction industry is highly vertically integrated. In the construction industry in Europe and America, the level of vertical integration differs from other manufacturing industries. In other words, most manufacturing industries, such as car, home electronics and food industry, perform the whole range of product operations: merchandise marketing, planning, design, production, sales, and service. Yet in the construction industry in Europe and America, an independent architectural design office or a consulting office usually designs buildings, and the construction companies specialize in the building work. The underlying principle of this system is that, by checking each other's work, the designer and the constructor enhance the quality of the completed products. However, their initial condition does not guarantee the long-term quality of the products. Therefore, it seems that the system to separate designers from constructors has developed from a desire to ensure highquality buildings that can stand the test of time by applying a strict quality check throughout the construction work processes (Hasegawa, 1988).

In contrast, construction companies in Japan usually perform both design and construction work, and this is particularly true for private projects. This dual performance is probably attributable to a sense of "confidence" between the client and the contractor, consolidated over many years. As suggested by the utility of design and production taken for granted in 
manufacturing industries, it may be more natural from the standpoint of corporate management if construction companies perform both design and construction work. This will make the construction company better able to perform the budgetary planning, production control, and maintenance service that will produce most benefits. Thus the separation of design from construction, regarded as a matter of course in Europe and America, is not assumed in Japan.

As examples of combined design and construction work, large Japanese general contractors, such as Kajima, Obayashi, Shimizu, Taisei, and Takenaka, hold design departments staffed by as many as one thousand architects and structural, mechanical, electrical, and other engineers (Hasegawa, 1988). These design departments compete with leading specialized architectural firms in the scale and scope of business activities. The design departments are always involved in the projects contracted by the marketing departments and, therefore, must handle many diverse construction orders. The design departments are also actively engaged in the development of new design technologies, such as CAD systems. The design department makes a vital contribution to the company management by adopting new technologies for practical use and by reducing construction costs and upgrading product quality hand in hand with the construction work department.

\subsubsection{Design-Build Delivery System}

As mentioned in the previous section, the most distinctive feature that illustrates Japanese general contractors is that they apply the design-build delivery system. The design-build delivery system is characterized by the following two traits: the one entity and fast-track approaches.

\section{One Entity Approach}

In the design-build delivery system, the owner retains a single entity that provides both design and construction services for a project. Two major differences exist between designbuild and "traditional" project delivery systems. First, with design-build, project 
responsibility and control is the hands of a single entity from concept through design and construction to completion. Second, design-build includes the early design level at which a construction contract price is agreed upon.

\section{$\underline{\text { Fast-Track Approach }}$}

With fast-track construction, a portion of the construction is started before the design is complete. This project delivery method is more about scheduling and sequencing of the project than it is about contractual relationships among the parties. Owners use fast-track as a way of obtaining occupancy/use of their project earlier, thereby generating revenue sooner or reducing costs. The fast-track approach shortens the overall project delivery period by performing much of the design and construction work concurrently rather than successively (ASCE, 1992).

For these reasons, the design-build project delivery system is more suitable for introducing IT in the construction industry than other delivery systems. Furthermore, compared to the architectural design work, the engineering design work has more potential to benefit from the investment in IT (Brochner, 1990). Therefore, LINCS, an IT project developing in a design-build organization and originating from the structural database, is a good start to integrate the whole design-construction project.

\subsubsection{Economic Environment in the Japanese Construction Industry}

Although the Japanese economy is said to be bouncing back, the economy is still stagnating and many companies including general contractors have not yet recovered from the damages of Bubble Economy. Their financial difficulties critically influence their management strategies. Therefore, it is important to mention the effects of Bubble Economy on the Japanese construction industry.

The so-called "Plaza Agreement" in September 1985 and the low interest rate policy of the 
Japanese government stimulated the investments in real estates and the development projects (Kanemoto, 1999). These movements caused the Bubble Economy in the mid 1980 's in Japan. During the Bubble Economy, private sectors actively invested in the redevelopment of city areas and the construction of office buildings; therefore, the sales of general contractors were dramatically increased. Moreover, the Bubble Economy affected the general contractors in some ways other than the rapid growth of their sales.

First, the Bubble Economy forced the general contractors invest substantial amount of money in their capital. The reason is that the general contractors had to purchase laborsaving machines to cope with the labor shortage caused by the increase of construction projects.

Second, since the general contractors invested actively in research and development during the Bubble Economy, construction technology was improved and therefore, construction productivity was increased.

To summarize, Bubble Economy consequently provided general contractors an opportunity to maintain and improve their infrastructures. Although Bubble Economy brought about financial difficulties, it is time for general contractors to apply appropriate IT systems in order to utilize their infrastructures.

\subsubsection{The Position of IT in the Japanese Construction Industry}

This section presents the position of IT in the Japanese construction industry. It includes the general overview of the condition of IT in Japanese companies and specific analysis of the position of IT in the Japanese general contractors.

\subsubsection{IT in Japanese Companies}

Although most executives in the Western companies recognize the importance of IT, their 
experience with it as a strategic business tool is often frustrating (Bensau and Earl, 1998). Bensau and Earl pointed out five problems which executives in the West face about IT:

- IT investments are unrelated to business strategy,

- Payoff from IT investments is inadequate,

- There's too much "technology for technology's sake,"

- Relations between IT users and IT specialists are poor, and

- System designers do not consider users' preferences and work habits.

Companies have spent millions of dollars on consulting fees trying to resolve these problems. However, these problems still remain unsolved and annoy top managers.

On the other hand, Japanese companies have not yet experienced these problems that are so common in the West. Japanese companies' expenditures on IT are perhaps less than half that of Western companies. Adoption of many modern technologies has been slow. For example, the ratio of PCs per capita in Japan compared with the U.S. is one to six. In short, Japanese companies lag behind the West in IT and Japanese managers could learn from U.S. and European practices. Table 3.1 shows the differences of attitude toward IT between Western and Japanese managers. In the construction industry, the tendency is thought to be the same. The following section discusses the details.

\subsubsection{IT in Japanese General Contractors}

As development in construction equipment and innovations in construction technology progresses, construction work evolves in scale, complexity, and diversity. At the same time, the demand for better quality and reduced construction periods grows. To cope with this, there is now a need for IT that can treat all phases of the construction work, such as marketing, planning, design, construction, operation, and maintenance. In this regard, a number of possible innovations can be imagined. 
Table 3.1 Comparison of IT Framework between Western and Japanese (adopted from Bensau and Earl, 1998)

\begin{tabular}{|l|l|l|}
\hline \multicolumn{1}{|c|}{ Issue } & \multicolumn{1}{|c|}{ Western Framing } & \multicolumn{1}{c|}{ Japanese Framing } \\
\hline $\begin{array}{l}\text { How do we decide } \\
\text { what information } \\
\text { system s our bu siness } \\
\text { needs? }\end{array}$ & $\begin{array}{l}\text { Strategic Alignment } \\
\text { We develop an IT strategy that } \\
\text { aligns with our business strategy. }\end{array}$ & $\begin{array}{l}\text { Strategic Instinct } \\
\text { We let the basic way we } \\
\text { compete, especially our } \\
\text { operatoinal goals, drive IT } \\
\text { investments. }\end{array}$ \\
\hline $\begin{array}{l}\text { How will we know } \\
\text { whether IT } \\
\text { investments are } \\
\text { worthwhile? }\end{array}$ & $\begin{array}{l}\text { Value for Money } \\
\text { We adapt capital-budgeting } \\
\text { processes to manage and } \\
\text { evaluate IT investments. }\end{array}$ & $\begin{array}{l}\text { Performance Improvement } \\
\text { We judge investments based } \\
\text { on operational performance } \\
\text { inprovements. }\end{array}$ \\
\hline $\begin{array}{l}\text { When we're trying to } \\
\text { improve a business } \\
\text { proce ss, how does } \\
\text { technology fit into } \\
\text { your thinking? }\end{array}$ & $\begin{array}{l}\text { Technology Solutions } \\
\text { We assume that technology } \\
\text { offers the smartest, cheapest } \\
\text { way to improve performance. }\end{array}$ & $\begin{array}{l}\text { Appropriate Technology } \\
\text { We identify a performance goal } \\
\text { and then select a technology } \\
\text { that helps us achieving it in a } \\
\text { way that supprots the people } \\
\text { doing the work. }\end{array}$ \\
\hline $\begin{array}{l}\text { How should IT users } \\
\text { and IT specialists } \\
\text { connect in our } \\
\text { organizations? }\end{array}$ & $\begin{array}{l}\text { IS User Relations } \\
\text { We teach specialists about } \\
\text { business goals and develop } \\
\text { thchnically adept, business-sany } \\
\text { ClOs. }\end{array}$ & $\begin{array}{l}\text { Organizatoinal Bonding } \\
\text { We encourage integration by } \\
\text { rotating managers through the } \\
\text { IT function, colocating } \\
\text { specialists and users, and } \\
\text { giving IT oversight to } \\
\text { executives who also oversee } \\
\text { other functions. }\end{array}$ \\
\hline $\begin{array}{l}\text { How can we design } \\
\text { systems that improve } \\
\text { organizational } \\
\text { performance? }\end{array}$ & $\begin{array}{l}\text { System Design } \\
\text { We design the most technically } \\
\text { elegant system possible and ask } \\
\text { employees to adapt to it. }\end{array}$ & $\begin{array}{l}\text { Human Design } \\
\text { We design the system to make } \\
\text { use of the tacit and explicit } \\
\text { knowledge that employees } \\
\text { already possess. }\end{array}$ \\
\hline
\end{tabular}

As multimedia and its capability of handling mixed test, numerical, image, and sound data, come into widespread use, it will become possible to structure functional databases for all phases of construction including marketing, planning, design, construction, operation, and maintenance; this will be a great step forward to construction management. Figure 3.1 shows the workflow of a construction project and the related databases. During marketing and planning, for example, the availability of data on land information and conditions experienced during past construction work will allow rapid optimization and preparation of 


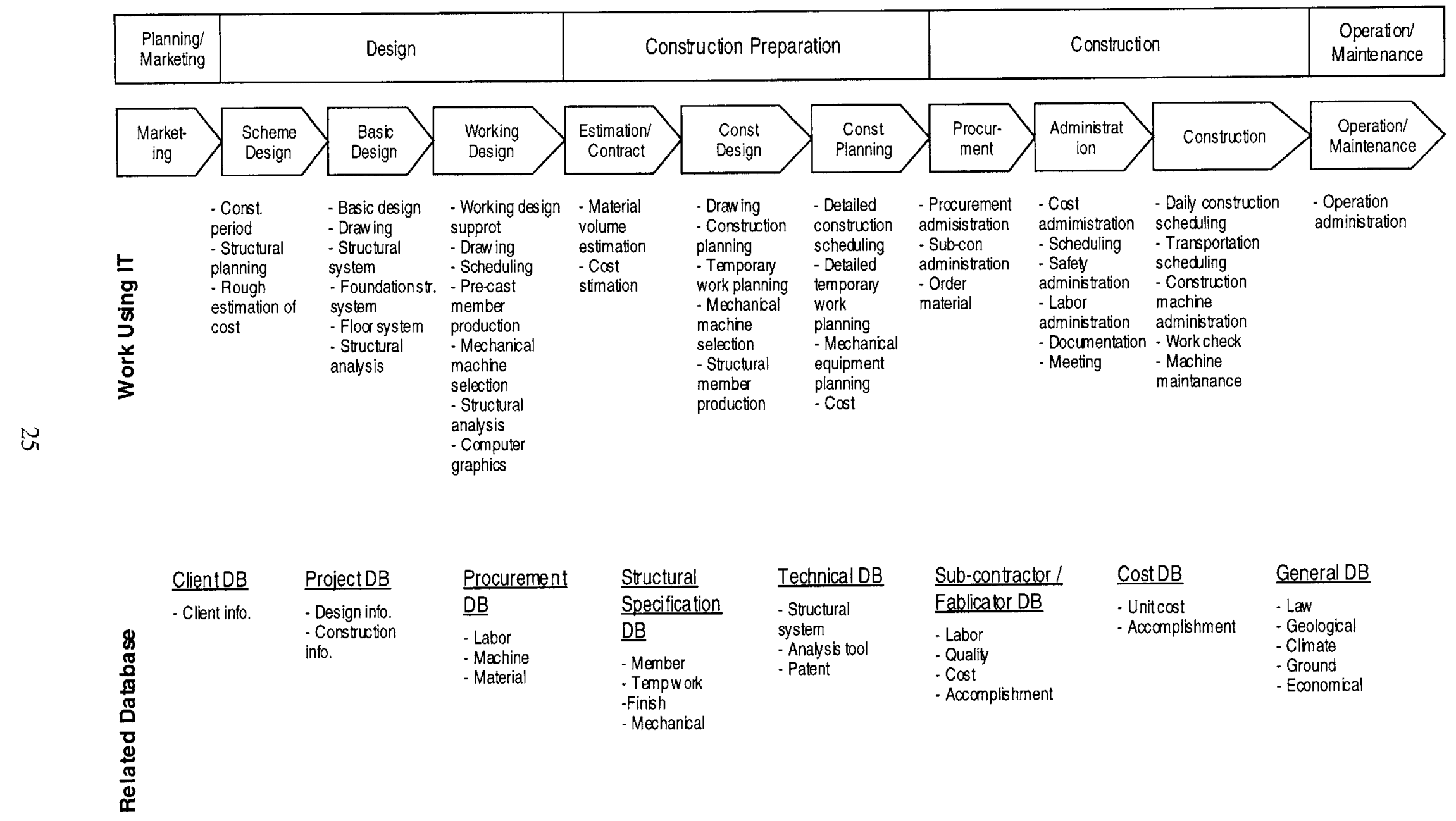

Figure 3.1 Typical Construction Project Workflow and Related Databases 
project plans. During the design and construction phases, construction will be automated according to design data prepared using $\mathrm{CAD} / \mathrm{CAE}$ and other design and drawing tools. We will then enter an age of information-oriented construction work, in which values predicted during the design stage are compared with feedback from actual results. As this type of information-oriented construction control develops through the use of multimedia techniques, construction will evolve into a form of Computer Integrated Manufacturing (CIM), as seen on production lines. The operation and maintenance phase will benefit from the use of databases structured during the design and construction phases. The significance of construction management technology will increase, as it becomes an interface between various phases of construction (Betts, et al., 1991).

In spite of the potential benefit by applying IT to the construction industry, one issue in the implementation of IT distinguishes construction from other sectors. It is the integration problem: how to exchange information among different designers, engineers, contractors, and owners. This problem has been the subject of study of natural level projects in Finland (Bjork, 1985) and other Nordic countries, but is far from being resolved. A relatively easy approach to solving this problem would be for all participants to use the same information systems and share their central database. It is now technically possible to exchange data between dissimilar systems; therefore, the use of the same information system is imperative. The LINCS system, mentioned in the next chapter, is exactly an example of practicing this central database concept.

The following paragraphs analyze the role of IT for each participant in a construction project: architects, engineers, and contractors.

\section{$\underline{\text { IT for Architects }}$}

Architectural design is a very intuitive activity with the creative abilities of the architect playing an important part. The architect needs to confer with the client, engineers, contractors and maintenance managers. These communications, which should take place frequently, are at present limited to a few meetings to resolve major design or construction 
problems, and rarely to discuss perceived maintenance problems. The proponents of the current CAD systems believe that the use of CAD will resolve these problems, indeed assuming that the integration problem addressed above can also be satisfactorily resolved.

The current $\mathrm{CAD}$ systems are design aids that allow predefined components or parts to be assembled, in two or three dimensions. As such, these are well suited for engineering design activities. Architectural design is not, and will not be in the immediate future, a process of assembly of parts. An architect, and other members of the design team, views a building as a three-dimensional object, a spatial concept, but a constructor perceives it as an assemblage of walls, beams, floors, and so on. The current CAD systems are therefore not suited to the early, sketch design stage. Current CAD systems are mainly useful as drafting tools, at the detailed design stage, for generating production information or working drawings.

\section{$\underline{\text { IT for Engineers }}$}

Drawings that are produced by handwriting or on CAD systems are used exactly in the same form in later stages. On the contrary, CAD systems used in engineering design are different: information from a CAD data file can be fed into the structural analysis software. The use of a CAD system does not, at the present time, provide any benefits at later stages in the construction process. It only provides savings in drafting manpower. Architects' offices have recognized this inflexibility.

With electronic data exchange, files can be transformed over telephone lines from one office to another. It must again be noted that we are simply talking about transporting drawings from the architect to the structural engineer, or to the government agency responsible for building control. This will no doubt speed up the process of transporting files, but the use of CAD systems cannot yet speed up the structural engineers' work. The structural engineer has to generate the data needed for analysis and design and feed this into the computer. It should be noted that if changes were made to drawings at this stage, the engineer would have to go through the same tedious process once again. The drawings are 
also subject to engineer's misinterpretations.

\section{$\underline{\text { IT for Contractors }}$}

At the construction stage there are again many enterprises involved who may potentially use IT for a wide range of activities. One of these activities is the translation of the design into a constructed building and to follow our example through we can examine the problem of implementing a design at the construction stage.

The final working drawings and corresponding specifications for materials and components are given to the main contractor for construction on site. This information, be it on computer diskettes or on paper, is still subject to the contractors' own interpretation, which, all too often becomes misinterpretation. The main activities of construction operations do not fully benefit from current IT tools. The scheduling of construction activities can be done using advanced software known as Project Management systems, widely available for use on PCs. The information needed for this has to be generated from drawings. Once again the data in a CAD file is of no use. This, however, does not diminish the merits of project management software as stand-alone systems and the benefits they provide in planning and controlling construction activities. Nonetheless, IT has yet to solve the communication gap between designers and contractors.

Cash-flow planning, progress payments and claims, payrolls, accounting and all matters related to money transactions put a heavy burden on the contractors' offices. Excellent proprietary programs are available for all aspects of the contractor's office management, some of which even claim to integrate these with project planning. A number of these tasks can also be carried out using general productivity tools such as database management systems and spreadsheet programs. Project management systems have the ability to do basic resource planning, and the office management programs are now available in very integrated forms. However, all of these systems are really only productivity tools that can be used only to improve the internal productivity of an organization rather than strategically affecting competitiveness. 


\subsection{Internal Scrutiny}

This section presents the second step of the IT planning framework: internal scrutiny. Internal scrutiny analyses the relevant processes and function within a firm. First, I present the overview of Kajima Corporation, and second, I present the overview of the LINCS project.

\subsubsection{Analysis of Kajima Corporation}

\subsubsection{Profile}

History

Kajima was established in 1840 by Iwakichi Kajima, a 25-year-old master carpenter in Tokyo. In those days, Japan was in the Edo period and Kajima mainly engaged in the construction of daimyo's mansions and samurai's residences. However, after the abrupt visit of Admiral Perry's fleet to Japan in 1853, the Japanese government was forced to change its policy to open the country to foreign trade and diplomatic relations. Anticipating the future demand for Western-style buildings, Kajima rushed to learn Western construction technique and completed Japan's first Western-style building, the Ei-Ichiban-Kan, in the foreign settlement of Yokohama in 1860. Since then, Kajima has rapidly developed its size and operation by forecasting future trends in all types of construction-related needs. The Company's activities have encompassed the railway construction and electric power development that propelled Japan's initial modernization as well as the coastal industrial developments, high-rise structures, nuclear power plants, and maritime-related projects that helped the nation grow quickly to become an economic giant.

\section{$\underline{\text { Business }}$}

The following items compose the business of Kajima (Kajima Annual Report, 1998): 
- Contracting for the construction of civil structures and buildings;

- Engineering, managing, and consulting related to the survey, research, planning, design, supervising, and procurement of construction projects;

- Land development, residence construction, real estate trading, leasing, brokering, appraisal of real estate;

- Land surveying;

- Design, manufacture, sale and lease of construction machinery and equipment;

- Manufacture, sale and lease of construction materials;

- Acquisition, licensing, and sale of industrial properties, know-how, and computer software; and

- Activities related to any of the preceding items.

\section{Employees}

As of March 1997, Kajima employees include 13,000 consisting of architects, engineers, computer systems engineers, and support staff. Internationally, as one of Japan's leading construction companies, Kajima maintains subsidiaries in North America, Europe, and Asia and is active in construction and real estate development businesses around the world.

\subsubsection{Organization}

According to Porter (1985), a company that handles multiple value-adding steps in the construction process can be called vertically integrated. Kajima, as well as other large-scale Japanese general contractors, is a clear example of a vertically integrated company. Figure 3.2 illustrates the graphical concept of vertical integration in Kajima (Kennedy, 1997). The outer box represents a market domain in which Kajima operates and the oval represents the company's value-creating activities. The figure indicates that Kajima is highly vertically integrated. Kajima is capable of taking a project from conception, through development, design, and construction, resulting in a product produced and sometimes operated and maintained almost completely in-house. 


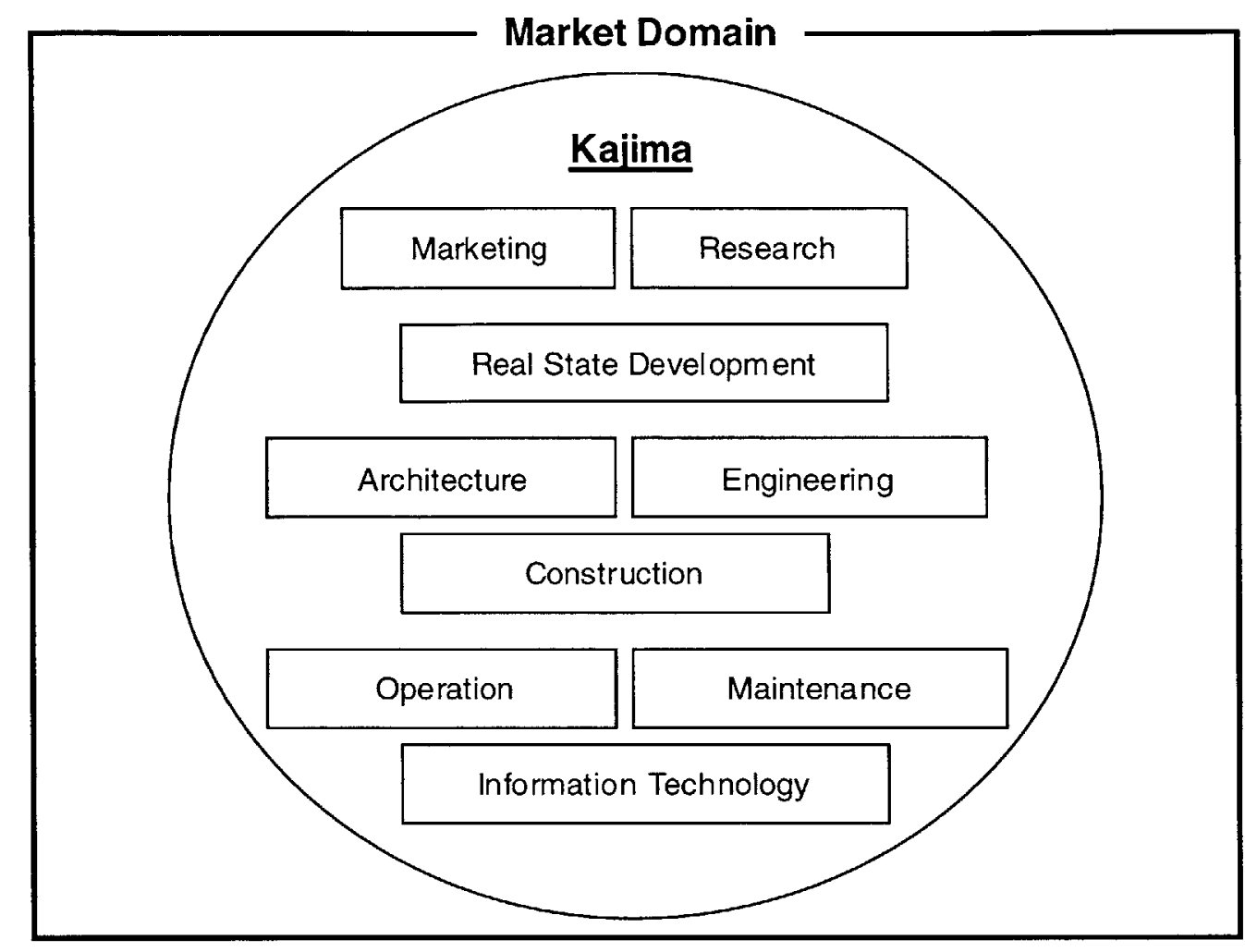

Figure 3.2 Vertical Integration of Kajima (adopted from Kennedy, 1997)

Figure 3.3 shows the organizations of Kajima Corporation and Figure 3.4 shows the relationship of each organization with the construction workflow. Under the supervision of the Head Office, Kajima's organization is divided into the following four groups according to its business goals: the Construction Group, the Architectural \& Engineering Design Group, the Real Estate Development Group, and the New Business Group. The Head Office also directly controls the Technical Research Center and the Information Processing Center.

\section{Construction Group}

Construction Group is the largest and the most important group in Kajima. This organization is in charge of the marketing, procurement, and construction work of projects. This organization also includes all the district branches in Japan and overseas. 


\section{The Architectural \& Engineering Design Group}

Design staff from the civil engineering design department and $\mathrm{A} / \mathrm{E}$ departments are equipped to handle design work for every conceivable construction-related project. They also assist Kajima designers and engineers posted overseas. The 200 -member Information Processing Center is yet another part of Kajima's total design team. The following is a partial listing of Kajima's comprehensive design services:

- Planning design

- Detailed design

- Specifications

- Bill of materials

- Procurement and other technical assistance

Kajima is particularly well known for its design achievements in such areas as:

- High-rise buildings

- Hotels, condos, and shopping centers

- High-tech buildings

- Educational, medical, and research facilities

- Manufacturing facilities

- Dams

- Nuclear, hydro, and thermal power generating facilities

- Large-sized dry-docks

- Port and offshore-related facilities such as sea berths

- Bridges, water storage tanks and other pre-stressed concrete structures

- Maritime construction

- Regional and urban development

To provide the highest quality and most economical construction services, Kajima has 
pioneered new technology, much of which is patented, in such areas as environmental protection, structural engineering and materials development.

\section{The Real Estate Development Group}

The Real Estate Development Group undertakes the development of office buildings, commercial facilities, residential buildings, hotels, resort facilities, and other projects while drawing on its superior design and engineering capabilities as well as state-of-the-art construction technologies created during more than 150 years of operations. The Company sells, leases, or manages its completed projects.

\section{The Information Processing Center}

The Information Processing Center (IPC) is the key department that manages communication needs throughout the entire company and is responsible for the information technology for various activities, e.g., construction, design, engineering, and development. IPC is broken down into 7 sections and is currently manned by roughly 200 staff: civil engineers, structural engineers, physicists, mathematicians, business managers, and engineering managers to ensure superior information processing environment from a group of specialists.

\section{The Kajima Technical Research Institute}

Kajima established the Kajima Technical Research Institute (KaTRI) in 1949 and it was the first construction research facility in the Japanese construction industry. R\&D activities in Kajima are centered at KaTRI as well as at a sister research institute, the Kobori Research Complex. In cooperation with their colleagues in the Company's civil engineering design, architectural design and the information processing center, some three hundred KaTRI researchers have developed numerous technological innovations in such fields as energy facilities, seismic engineering, soil engineering, bedrock and foundation studies, new materials and new construction methods. These innovations have made significant contributions to the construction industry in Japan and overseas. 


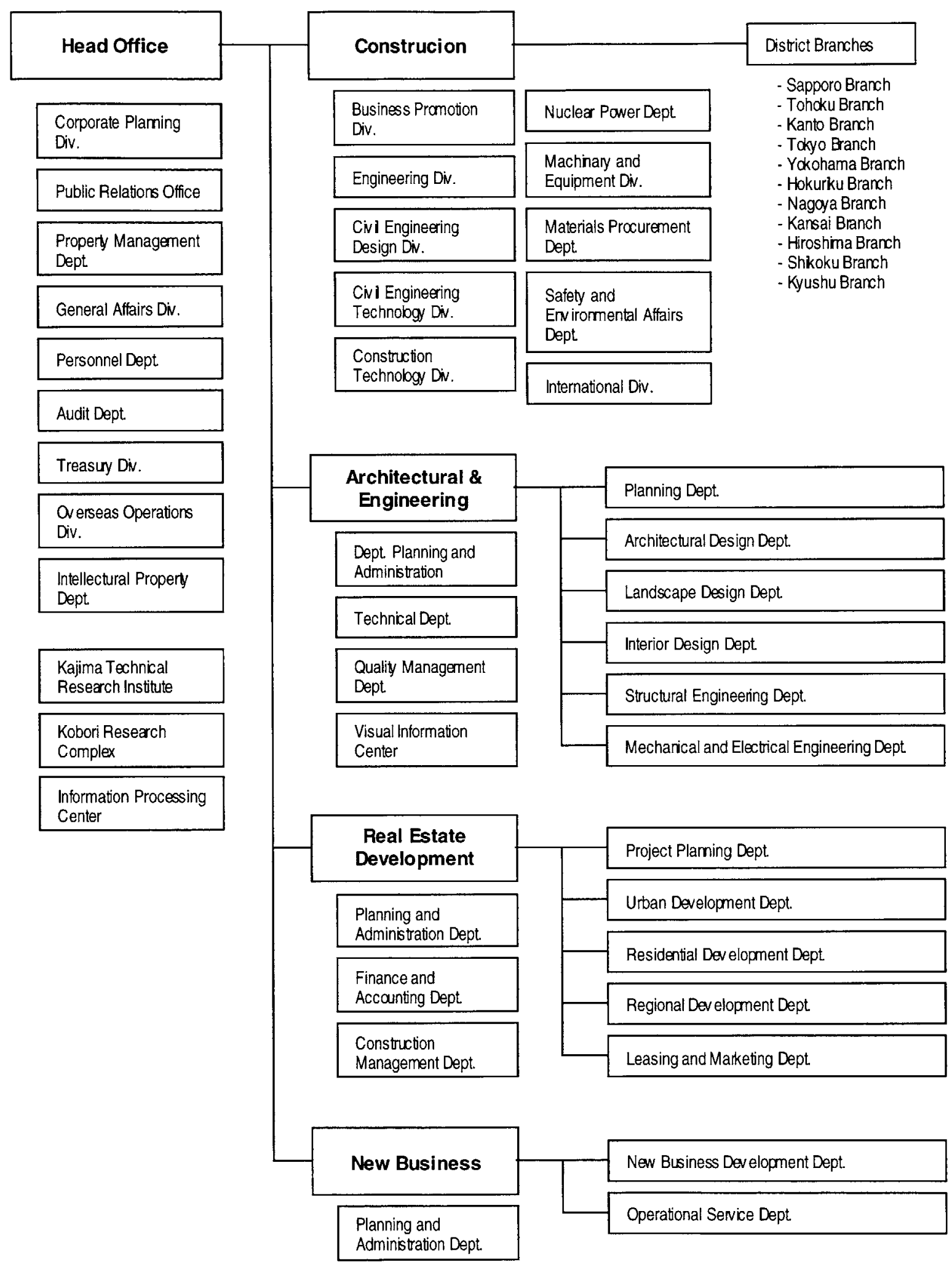

Figure 3.3 Organizations of Kajima (adopted from Kajima Brochure, 1997) 


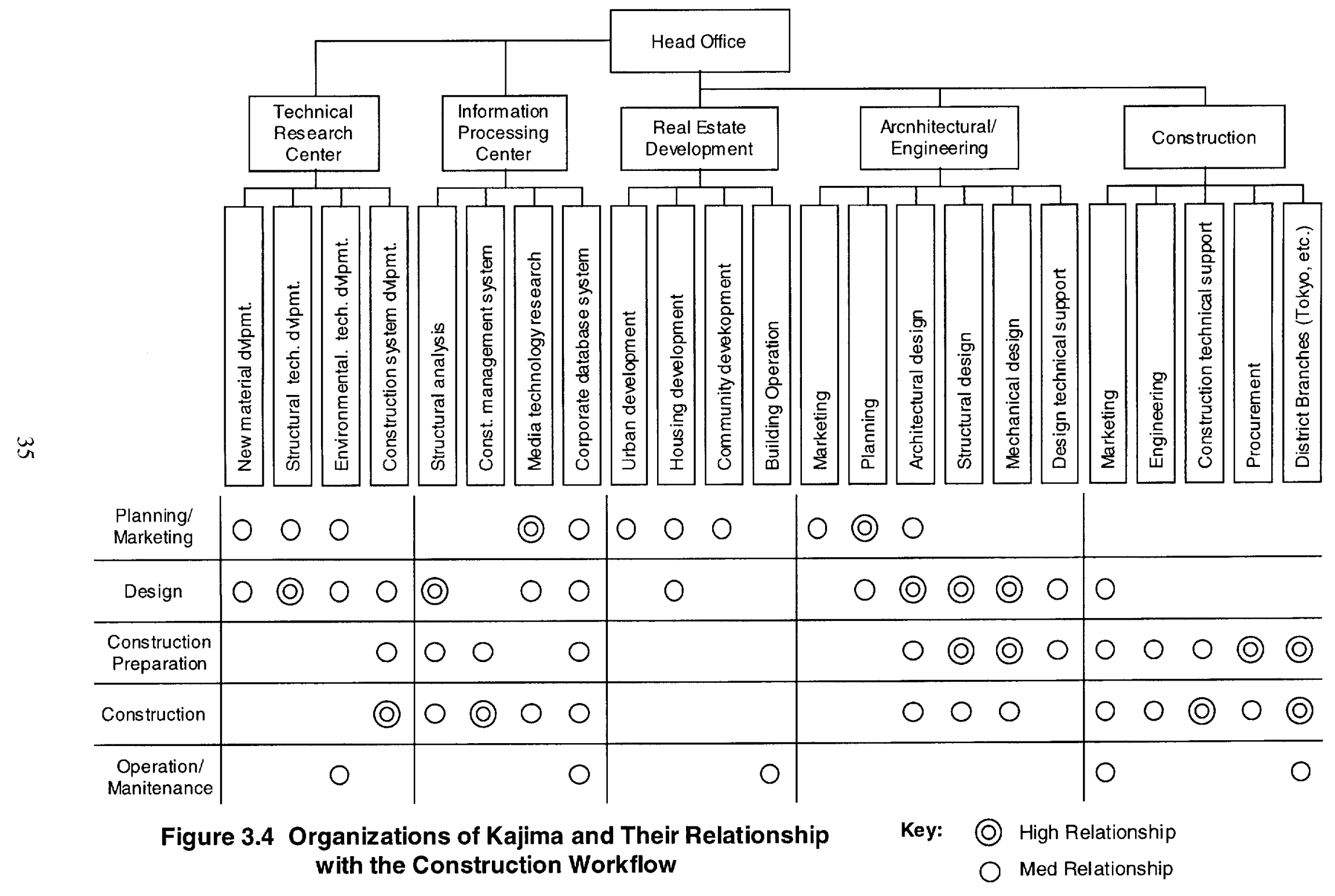




\subsubsection{IT Infrastructure}

Information is one of the major resources for corporate management and is backed by three major pillars in Kajima (Figure 3.5). The Information Processing Center (IPC) is the key department that manages communication needs throughout the entire company. "Promotion of Advanced Information" supports and deepens effective utilization of information sources through education and training on office automation. Some fields of "Research and Development" include numerical analysis, comprehensive systematization technology, Computer Integrated Manufacturing (CIM) and other fields in computer science. "Management and Control" supports the computer network that puts the whole company online. The current highly advanced information-oriented company is maintained by such activities.

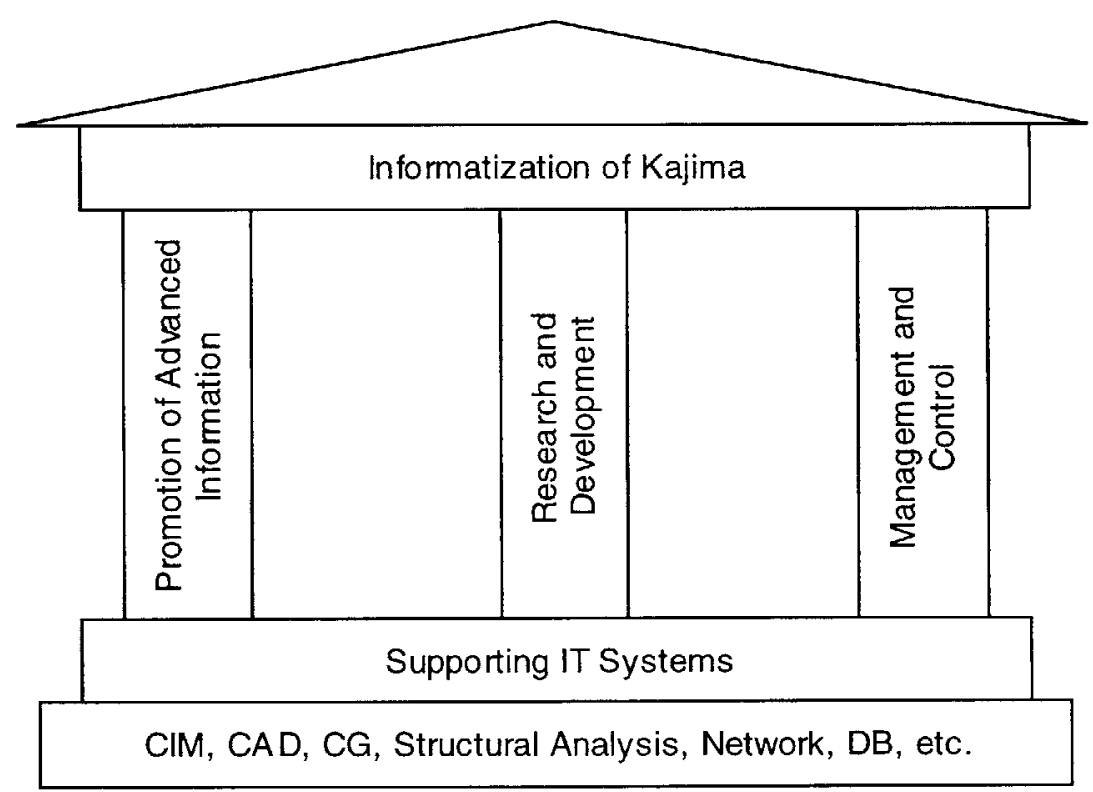

Figure 3.5 Three Pillars of Information Processing System in Kajima
(adapted from Kajima IPC Brochure, 1994)

\section{Promotion of Advanced Information}

Kajima's effort of promoting advanced information technology and communication systems focuses on the needs of the $21^{\text {st }}$ century and not on imminent conservation or cost 
lowering performance. Such goals are realized by close and sophisticated communication between various departments that will match the information technology demands of the $21^{\text {st }}$ century. IPC coordinates and supports in-house office automation. It ensures strategic utilization of information as the major data processing department in Kajima. Other duties include introducing various $\mathrm{OA}$ equipments and software, developing corporate-wide systems and supplying information infrastructure, for Kajima.

\section{$\underline{\text { Research and Development }}$}

IPC is involved in research and development in various fields of computer science from numerical analysis represented by structural analysis, and CIM (Computer Integrated Manufacturing) that is technology for general systematization of the lines. Kajima's R\&D in numerical analysis includes the use of supercomputers to analyze material and geometrical non-linearity, development of new discrete methods to analyze strong nonlinearity, and fluid analysis by unstructured meshes. R\&D in CIM includes construction of a general design and manufacturing system using CAD and CAE technology, employment of factory automation technology, and systematization of an integrated information system at the construction site. $\mathrm{R} \& \mathrm{D}$ in computer science includes development of object-oriented systems such as distributed multimedia database, virtual reality utilizing CG technology, artificial life related technology such as neuro, fuzzy, and chaos, and investigation and research of network computing related hardware and software technology and numerous other fields of research.

\section{$\underline{\text { Management and Control }}$}

The management and control system is the most important feature of the Company's computer performance to ensure smooth exchange and accumulation of information. Kajima's computer system is configured with large-scale mainframe and super computers at the head office that connect company-wide terminals all over the company through socalled KI (Kajima Intelligent) Network for real-time information exchange. System security is also maintained throughout all stages with a double-check system to protect corporate 
information from unauthorized access. This means the computer screens for user qualification and passwords upon logging in. In addition, it stores files in a hierarchy depending on the level of confidentiality to ensure further safety. Needless to say, IPC makes every effort to introduce the most advanced technology and systems in computer and networking systems in hope to promote user friendliness and utilization. All-in-all, the department covers a broad range of duties such as servicing and repairing equipment, offering advise upon adding new terminals and networking devices, scheduling regularbase data processing, and managing peripheral equipment.

\subsubsection{Information Flow inside Kajima}

It is of great use to know what links between different processes and functions inside a firm exist and what information flows control the normal production workflow. Figure 3.6 and Table 3.2 give a generic overview about the processes and the associated information flows at the level of Kajima. It can be a basis for the analysis of information needs inside the firm, and is a starting point for evaluating potential IT investments.

\section{Research \& Development}

In the $R \& D$ stage, the evaluation of technological performance and profitability is important to establish strategic R\&D planning, however, the evaluation does not necessarily need advanced IT systems. Information needed for this evaluation comes from the monitoring of construction as well as the monitoring of R\&D transactions. R\&D transactions, on the other hand, require highly advanced IT systems to handle staggering experimental data and to analyze structural/environmental behavior of buildings. For example, Kajima is developing a system for the analysis of complex nonlinear behavior and testing of the earthquake response of reinforced concrete, steel/concrete, and other composite structures. Although these systems have been recognized for their performance, they need further development for more accrete and swift analysis. 


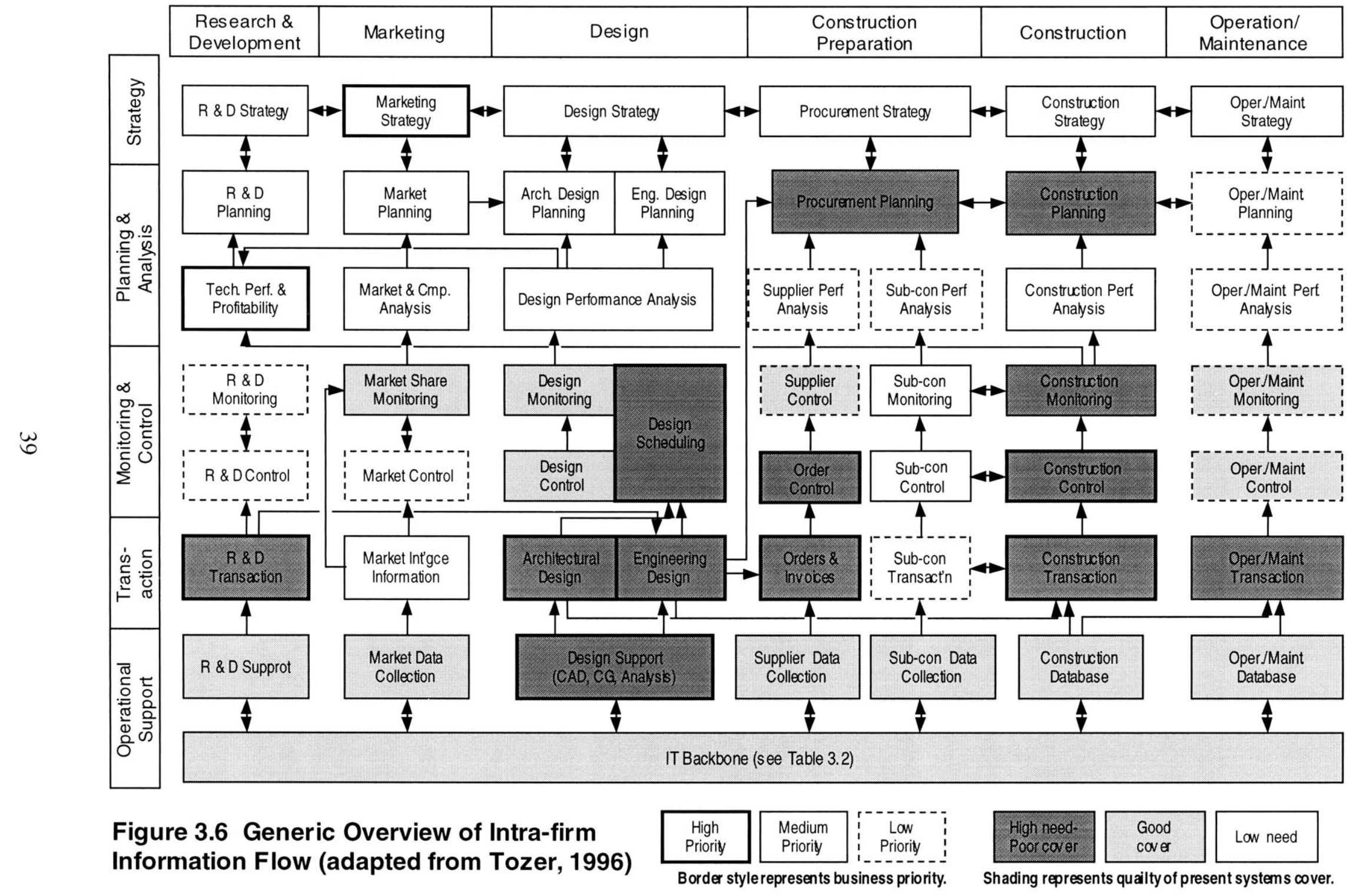


Table 3.2 IT Backbone of Kajima

\begin{tabular}{|c|c|c|c|c|c|c|}
\hline & $\begin{array}{l}\text { Research and } \\
\text { Development }\end{array}$ & Marketing & Design & Procurement & Construction & $\begin{array}{l}\text { Operation/ } \\
\text { Maintenance }\end{array}$ \\
\hline Infrastructure & $\begin{array}{l}\text { - Hardware } \\
\text { - Network } \\
\text { - PC } \\
\text { - Super } \\
\text { computer }\end{array}$ & $\begin{array}{l}\text { - Hardware } \\
\text { - Network } \\
\text { - PC }\end{array}$ & $\begin{array}{l}\text { - Hardware } \\
\text { - Network } \\
\text { - PC }\end{array}$ & $\begin{array}{l}\text { - Hardware } \\
\text { - Network } \\
\text { - PC }\end{array}$ & $\begin{array}{l}\text { - Hardware } \\
\text { - Network } \\
\text { - PC } \\
\text { - Super } \\
\text { computer }\end{array}$ & $\begin{array}{l}\text { - Hardware } \\
\text { - Network } \\
\text { - PC } \\
\text { - Super } \\
\text { computer }\end{array}$ \\
\hline $\begin{array}{l}\text { Communi- } \\
\text { cation }\end{array}$ & $\begin{array}{l}\text { - Inter-intra net } \\
\text { - E-mail } \\
\text { - Remote } \\
\text { meeting }\end{array}$ & $\begin{array}{l}\text { - Inter-intra net } \\
\text { - E-mail } \\
\text { - Conference } \\
\text { system }\end{array}$ & $\begin{array}{l}\text { - Inter/intra net } \\
\text { - E-mail } \\
\text { - Client/Server } \\
\text { - Remote } \\
\text { meeting }\end{array}$ & $\begin{array}{l}\text { - Inter/intra net } \\
\text { - E-mail }\end{array}$ & $\begin{array}{l}\text { - Inter/intra net } \\
\text { - E-mail } \\
\text { - Sign board } \\
\text { - Remote } \\
\text { surveillance } \\
\text { system }\end{array}$ & $\begin{array}{l}\text { - Inter/intra net } \\
\text { - E-mail } \\
\text { - Operation } \\
\text { surveillance } \\
\text { system } \\
\text { - Defect detect } \\
\text { system }\end{array}$ \\
\hline Application & $\begin{array}{l}\text { - Environmental } \\
\text { analysis system } \\
\text { - Structural } \\
\text { analysis system } \\
\text { - FEM/DEM }\end{array}$ & $\begin{array}{l}\text { - Presentation } \\
\text { support } \\
\text { - Computer } \\
\text { graphics }\end{array}$ & $\begin{array}{l}\text { - CAD } \\
\text { - Expert system } \\
\text {-Computer } \\
\text { graphics } \\
\text { - Structural } \\
\text { anaylysis system } \\
\text { - Visualization }\end{array}$ & $\begin{array}{l}\text { - CAD } \\
\text { - Procurement } \\
\text { management } \\
\text { sysetem }\end{array}$ & $\begin{array}{l}\text { - CAD } \\
\text { - Construction } \\
\text { management } \\
\text { system } \\
\text { - Safety } \\
\text { management } \\
\text { system } \\
\text { - Construction } \\
\text { automation }\end{array}$ & \\
\hline
\end{tabular}




\section{Marketing}

In the marketing stage, the amount of market data collected decides whether a company organizes a superior marketing strategy or not. Therefore, effective collection and utilization of information is gaining attention as the fourth business resource following human, material and financial resources. The information resource in Kajima is supported by constant updates and effective utilization of a database in various activities of the construction process. Kajima's online database system employs the Kajima Intelligent network to offer comprehensive information on management, sales, and technological support, from any terminal at any time.

\section{$\underline{\text { Design }}$}

In the design stage, architectural/engineering design information created becomes the core data in the following construction work. Creating this data requires a significant IT support, such as CAD, CG and other analysis software. However, this software is currently used as stand-alone systems and there is substantial waste of workload in exchanging data among architects and engineers. In addition, this inefficiency of data exchange occurs between design and construction stages. The LINCS system, explained in detail in the next section, is expected to solve these problems by sharing a single database among all the participants in a project.

\section{Construction Preparation / Construction}

In the construction stage, smooth management of the working site requires more sophisticated information and flexible measures to swiftly attend and support various onsite needs. Response time can be minimized by incorporating systems that can automatically process such information and swiftly respond to the user's needs. Kajima has been actively involved in improving the worksite by developing a budget management system, CAD blueprint system, in/out record of workers, various key control systems and a 3D process control systems to further consolidate and improve the worksite management system. For example, the conference support system in the "intelligent" (high-tech) room at 
the worksite that is complete with a large screen includes information from computers and visual information from VTR and electronic cameras for more efficient communication. In addition, multi-media information can be easily accessed since construction and inspection records are all stored on image databases. High-level information technology of on-site management methods not only simplifies work and heightens efficiency but also actualizes a worker-friendly site.

\section{Operation/Maintenance}

The most pressing operation/maintenance problems are more of management than information systems. The manufacturing industry currently faces unprecedented harshness with diversification in clients' needs, shorter delivery time, and rapid changes in the international situation. Accordingly, the needs for a more functional, efficient and high quality system in manufacturing and logistics facilities are increasing. Especially, construction of a Computer Integrated Manufacturing system to consolidate and share information all through the phases of research, design, manufacturing, sales, and logistics is required. For example, Kajima developed a system for automating the process of packing diverse products in shipping boxes at distribution facilities. This system allows the company to make uniquely superior engineering proposals with respect to the construction of pharmaceutical manufacturing plants and delivery facilities. A subsidiary company of Kajima is actually in charge of the job of operation and maintenance of buildings.

\subsubsection{Analysis of the LINCS Project}

\subsubsection{Background of LINCS}

Introduction of $\mathrm{CAD}$ applications to the $\mathrm{A} / \mathrm{E} / \mathrm{C}$ industry has brought many benefits to the design and construction work, such as speed, preciseness, and clearness. However, the application of information technology to the design and construction work is still restricted

to as a mere drawing machine and much of the building information are exchanged by the conventional human communication or printed drawings. Therefore, designers and 
construction site managers have to spend much work to adjust inconsistencies between drawings. According to a survey, $30 \%$ of all the questions came from construction site managers to designers were related to inconsistencies of drawings from architectural, structural and mechanical designers (Kajima Internal Report, 1998). We are in serious need to establish new synthetic information system in the design and construction industry.

\subsubsection{Basic Concept of LINCS}

Figure 3.7 shows a simple diagram of the configuration of information exchange in the design and construction industry. In the conventional manner, designers and construction site managers exchange building information by printed drawings. $\mathrm{CAD}$ applications are used inside each division, but it has almost no compatibility to CAD applications used in other divisions. Therefore, interdivisional exchange of information is mainly conducted by the human contact. On the contrary, in the proposed manner, information is unified and administered as a form of database stored in computer memories. Since the database is stored in a text format, any software can use the database. The database is converted into formats according to its software. Designers and construction site managers share the same source. Therefore, theoretically, no inconsistency occurs between drawings from different divisions.

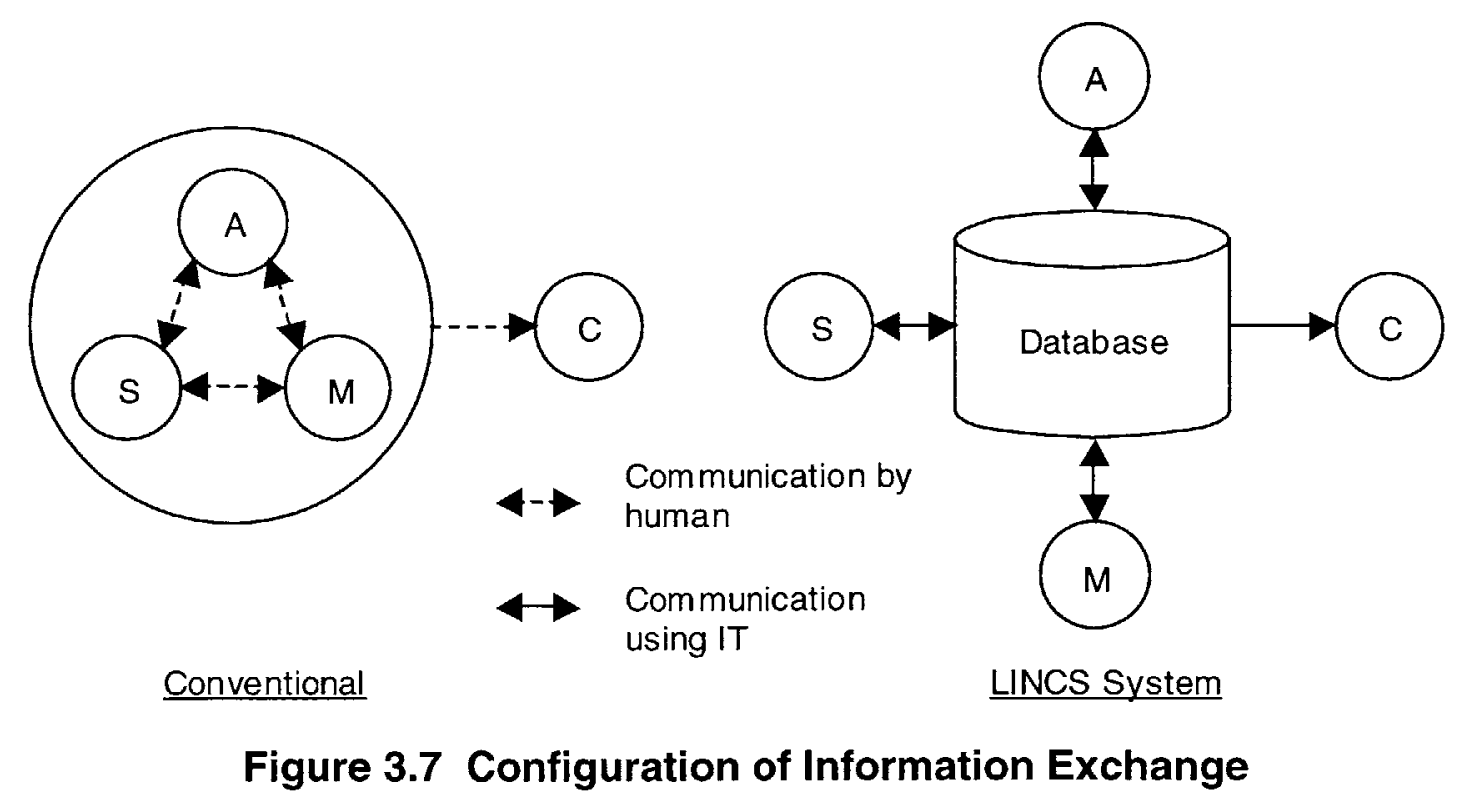




\subsubsection{Project Organization of LINCS}

Figure 3.8 shows the organization of the development of LINCS. The Information Processing Center is the key department that adjusts communication needs throughout the entire company and responsible for the information technology for various activities, e.g. construction, design, engineering, and development.

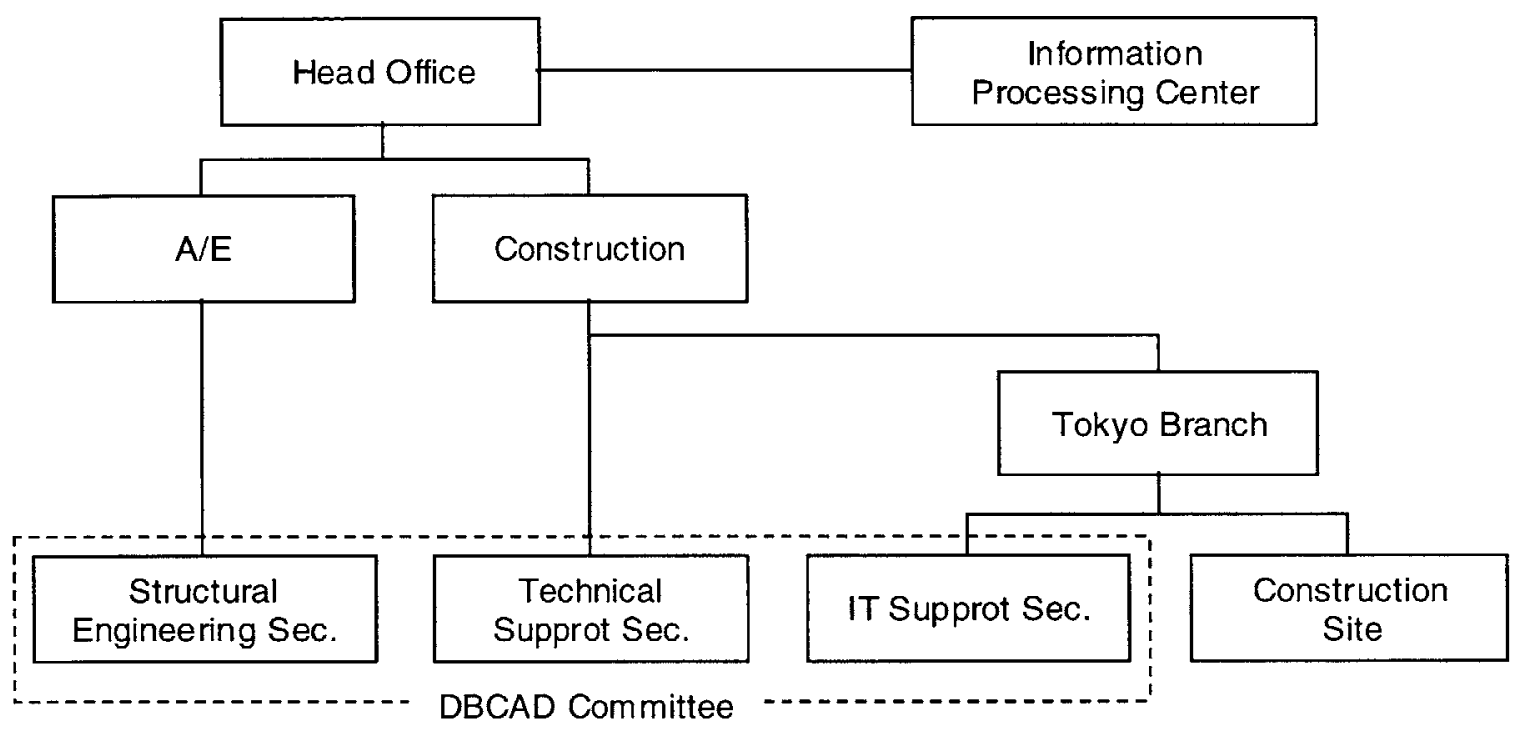

Figure 3.8 The Organization of the Development of LINCS

\subsubsection{Configuration of LINCS}

Figure 3.9 shows the IT infrastructure of the LINCS system and Figure 3.10 shows the relationship of LINCS with the construction workflow. These figures indicate that the structural database created by DBCAD forms the core of LINCS. The structural database is stored in text format, therefore, it can be easily transformed into other formats.

At the design stage, the structural database has brought about the following benefits. First, it enables the feedback of the results of analysis to the structural database. Feedback is possible because bi-directional information transmission occurs between the structural database and the structural analysis software. Second, structural drawings are drawn almost automatically from the structural database. It saves the great amount of time to redraw 
them. Third, since the structural database is linked to architectural and mechanical CAD applications, architects and mechanical engineers do not have to create their drawings from the beginning. The skeleton of a building is automatically created from the information of the structural database. Last, since the structural database is linked to the construction supporting systems, site managers can forecast the approximate cost at the early stage of design work. If the estimated cost exceeds the contract cost, they can order designers to change the design in order to match their cost.

At the construction stage, the structural database is linked to many construction-supporting applications. The greatest benefit is that construction drawings can be drawn with much less labor and time. The consistency of drawings is maintained firmly. Until now, subcontractors usually draw steel-frame drawings and reinforcing bar drawings. Linking structural databases to the CAD applications lowers the cost to draw these drawings. As a result, we can shorten the time between the project planning phase and the completion of construction.

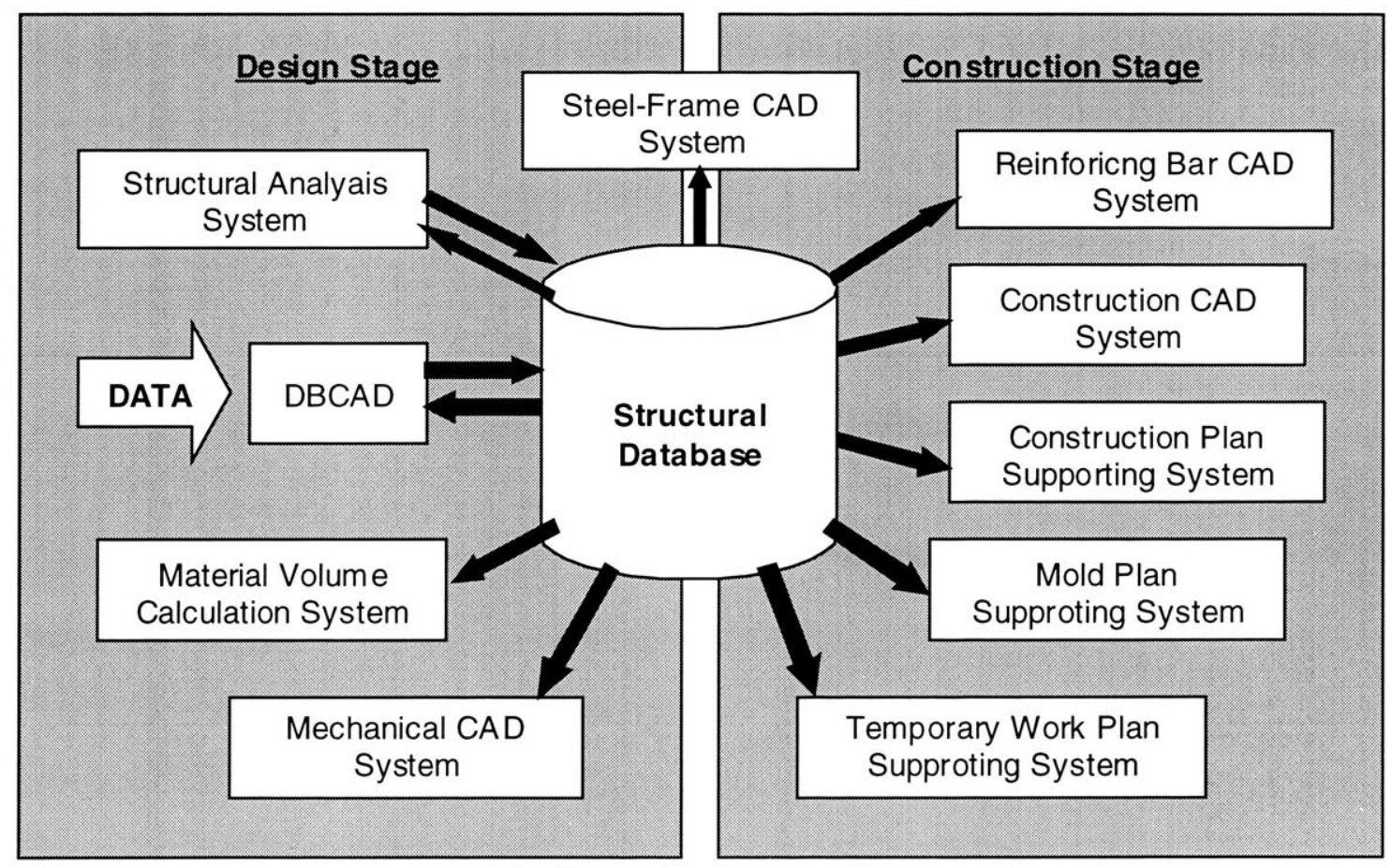

Figure 3.9 IT Infrastructure of LINCS 


\begin{tabular}{|c|c|c|c|c|}
\hline $\begin{array}{c}\text { Planning/ } \\
\text { Marketing }\end{array}$ & Design & Construction Preparation & Operation/ \\
Maintenance
\end{tabular}

a

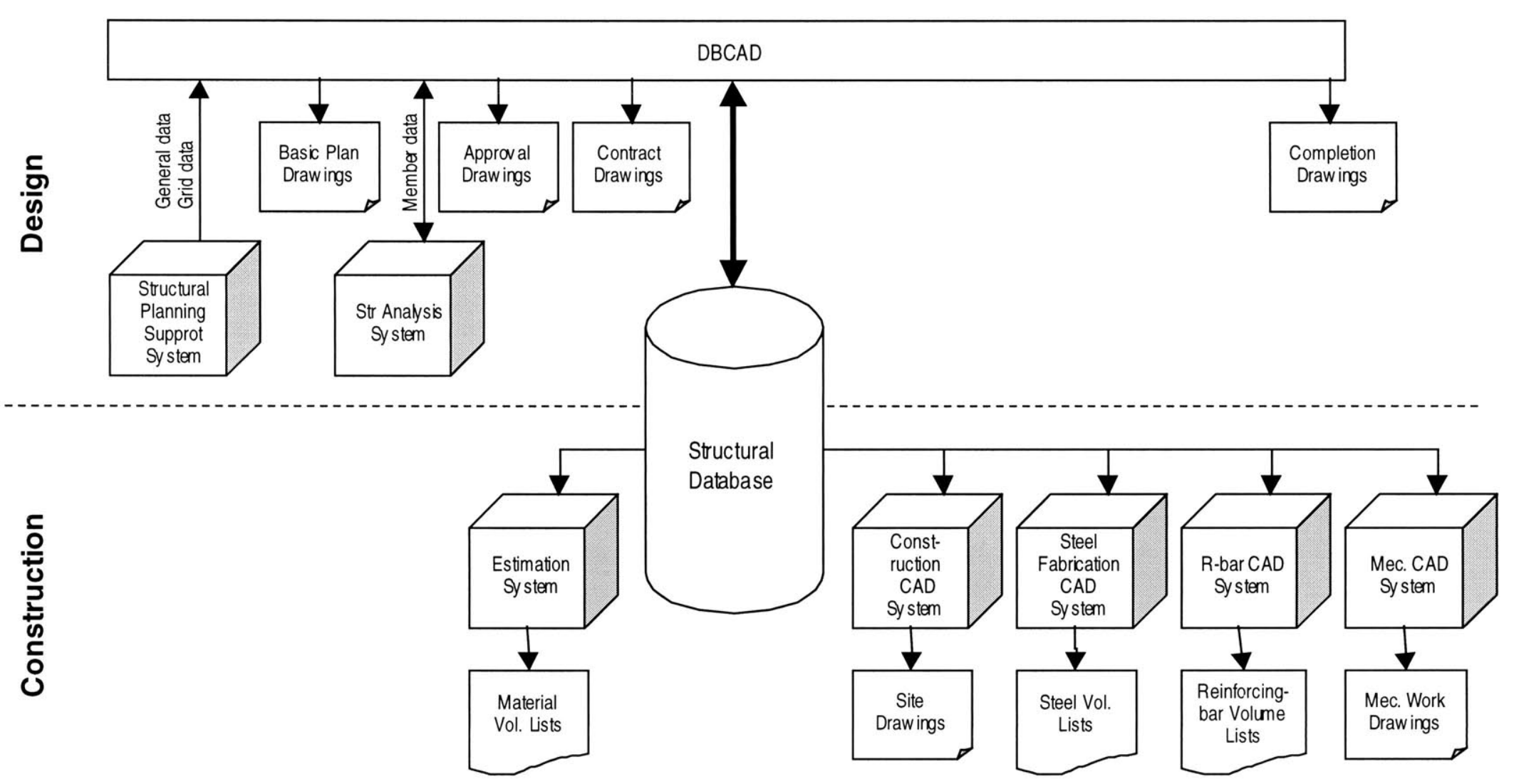

Figure 3.10 Relationship of LINCS with the Typical Workflow of Construction Projects 


\subsection{IT Diffusion Analysis}

This section presents the third step of the IT planning framework: IT diffusion analysis. IT diffusion analysis consists of the identification of the IT diffusion stage and the modeling of the IT diffusion within a company.

\subsubsection{Diffusion of the Level of Informatization}

When an investment in IT is made, a time lag occurs before that technology is adopted throughout the project and its full potential is harnessed (Weber and Peña-Mora 1997). This process of adoption is termed diffusion. Three main phases of IT diffusion have been identified (Hannah et al.) as follows.

1. "Substitution" of existing technologies

2. "Enhancement" of processes

3. "Transformation" of organization and strategy

Within each phase, the diffusion process is seen as a sequence of S-curves. They describe a stepwise progression. During this progression, structural, technological, and organizational barriers are overcome. Figure 3.11 shows the percentage of CAD-drawn drawings in the structural division in Kajima and clearly explains the S-curve diffusion process. In 1981, a CAD system was first introduced to the $\mathrm{A} / \mathrm{E}$ department in Kajima. In those days, the CAD system was costly and only three machines were supplied to the nearly one thousand employees in the department. For about ten years since the first introduction of the CAD system, additional purchase of CAD machines was limited and the number of CAD-drawn drawings slowly increased. In 1994, AutCAD® was installed in all the PCs of the employees in the department, and the percentage of CAD-drawn drawings increased dramatically. By the end of 1997 , CAD systems drew nearly $100 \%$ of the drawings. 


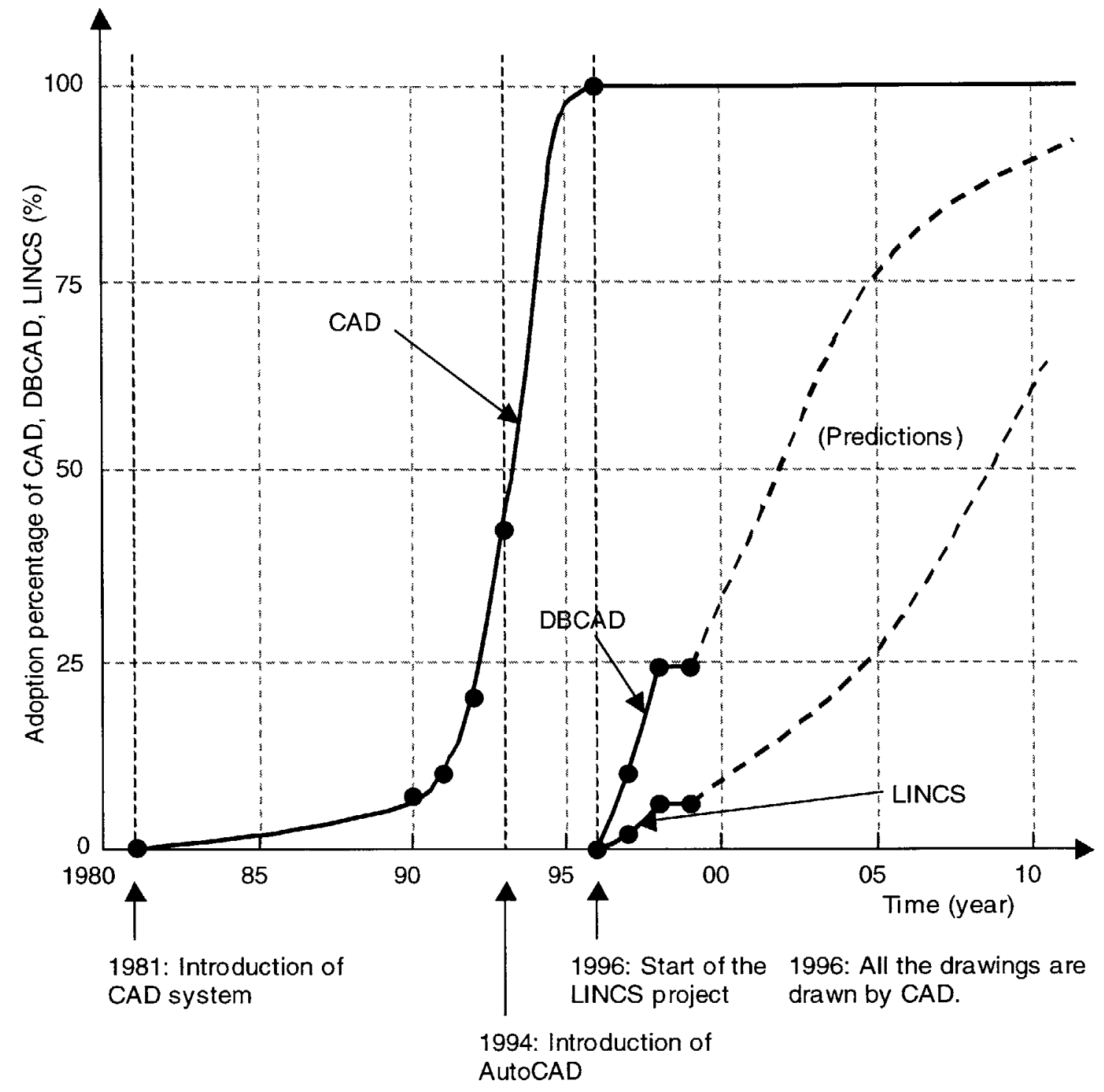

Figure 3.11 Adoption Percentage of CAD/DBCAD/LINCS in the Construction Projects in Kajima

\subsubsection{Substitution}

During the substitution phase, IT replaces the existing processes. The most remarkable example of this stage is the use of CAD as a "drawing machine." The traditional process of handwriting has been replaced by CAD applications and these CAD systems have superseded the handwritten drawing work in each design and construction phase. However, even if the $\mathrm{CAD}$ systems reduce the drawing time, each instance has to be drawn from a 
blank paper.

Another example of substitution is that expert systems automate some part of the design work. In the structural design process in Kajima, several expert systems, such as structural planning support system, foundation structure selection system and slab structure selection system, assist structural engineers especially in the basic design phase. Once a user inputs data needed for the system, it provides appropriate design information as if an experienced engineer judged it. However, in the substitution stage, design information obtained by those systems is not linked to other IT systems. Therefore, users have to manually input it into CAD systems, structural analysis systems, and other engineering systems.

The establishment of the LINCS system will bring about the following benefits to the design and the construction stages. In the design stage, designers can begin to use the DBCAD from the basic design phase. This can reduce the drawing time and save the input work to the structural analysis software, because the structural database is automatically transformed to the data format available to the structural analysis software. Also, computerizing drawing data transfer maintains the consistency among drawings. In the construction stage, the structural database is linked to the CAD software for site drawings and shop drawings so that the drawing work in the construction is reduced. Therefore, site managers can start the construction planning and order building materials earlier, and the procurement cost of these materials can be cut down.

\subsubsection{Enhancement}

During the enhancement phase, the organization realizes new, more effective, or efficient processes that increase quality or improve productivity on the project. For example, the appearance of structural computation programs has changed the approach to the structural design. As seen in Figure 3.12, the fundamental process of the structural design is an iterative procedure: structural engineers first decide the design load and assume the size of structural members, then compute the stress of members. If the stress of all the members does not satisfy the required stress, engineers change the size of the structural members and 
repeat the structural computation until it satisfies the criteria. To enlarge the size of members is a simple solution to satisfy the structural criteria, but the architectural and the economical limitations force engineers to design members that exactly satisfy the structural criteria. However, before the advent of structural computation applications, repeating the time-consuming structural computation was not realistic. Actually, engineers designed the optimal size of members from the first through their experience and intuition. After the appearance of structural computation applications, engineers can repeatedly execute the computation and search for more optimal members. Moreover, structural engineers can spend the saved time on more detailed examinations. This change of the design approach improves quality of the structural design.

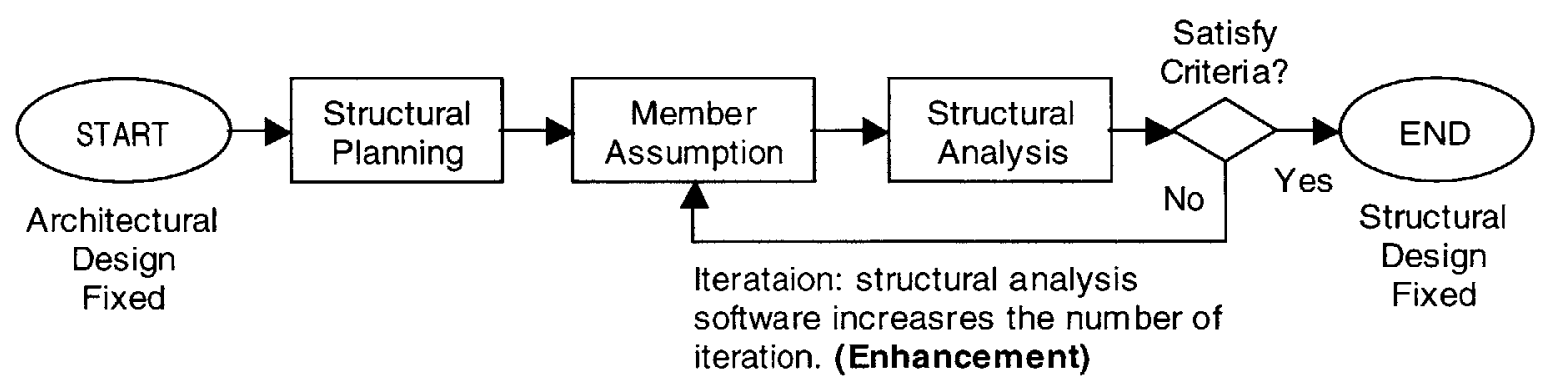

Figure 3.12 The Fundamental Process of Structural Design

\subsubsection{Transformation}

During the transformation phase, an IT strategy evolves to a point where IT forms a major part of the deliverable product. The LINCS project belongs in the beginning of this phase because the structural database realized the integrated design-build project where designers and contractors share a single database throughout the project.

LINCS has changed the structural design process. For example, the drawing work, no matter whether it was done by hand or CAD, started after the working design phase had been completed. In contrast, with the introduction of LINCS, the drawing work starts from the early stage of the basic design phase by inputting the design information using the DBCAD. Figure 3.13 shows the change of drawing process before and after the introduction of DBCAD. The traditional design process was sequential: The structural 
design proceeded in the order of the structure planning, assumption of members, structural computation, and drawing.

With the introduction of DBCAD, the design has come to proceed concurrently. First, the input and the output data from the structural planning support system, such as the general information of a building, column position, floor height, optimal member sizes, and materials, are linked to the structural database. Second, member sizes not available from the structural planning support system, such as slab and wall sizes, are assumed and input into the structural database. Finally, the structural database is linked to the structural computation system and its output is reflected in the structural database, which means that all the information needed for drawing is included in the structural database when member sizes output from the structural computation program satisfy the criteria. The DBCAD immediately produces structural drawings. The remaining work on the drawings is to add miscellaneous details not created by the DBCAD.

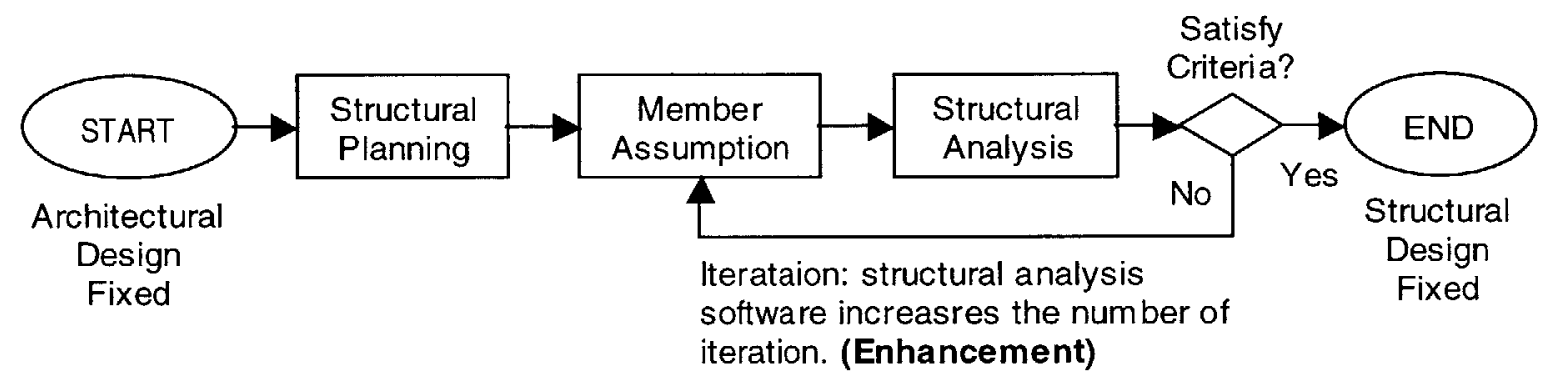

$\underline{\text { Structural Design Process }}$

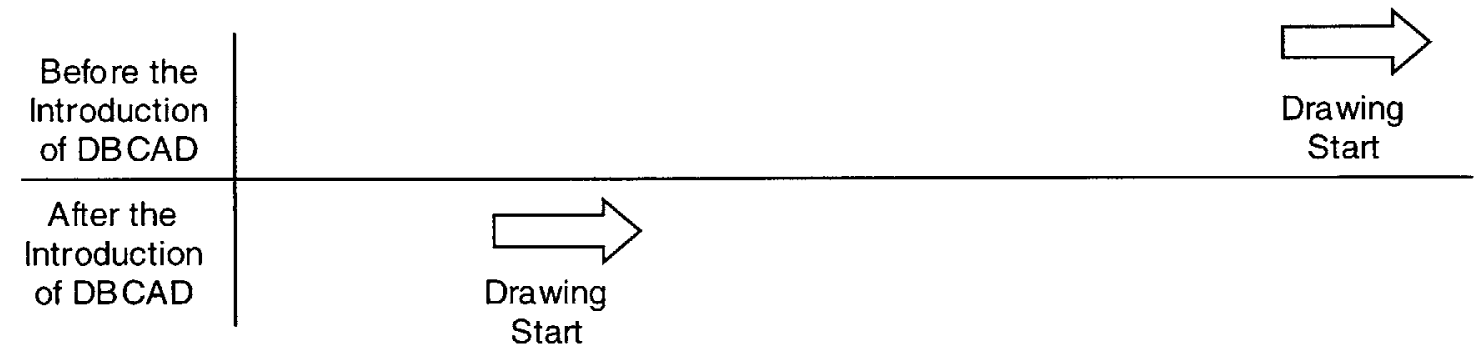

Without $D B C A D$, drawing work can be started once the structural planning is fixed.

With $D B C A D$, drawing work can not be started until the structural design is finished.

Drawing Work Process

Figure 3.13 The Change of Drawing Process in the Structural Design before/after the Introduction of DBCAD 


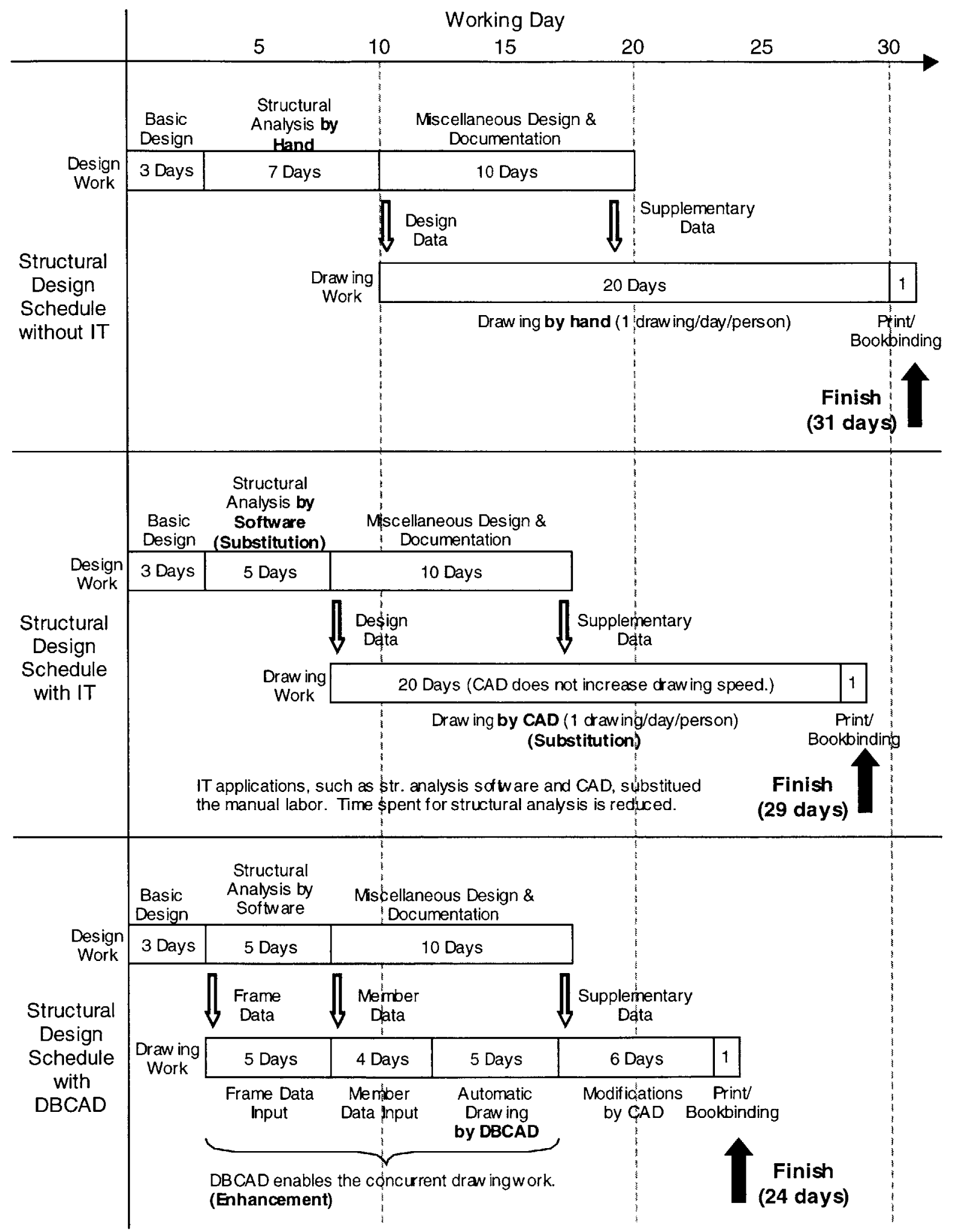

Figure 3.14 Changes of Structural Design Schedule with/without IT 
LINCS has also affected the scheduling in the design stage. Figure 3.14 shows a design schedule of a building project. Due to the substantial time saving in the drawing process, engineers could spend more time on the basic design phase and the slab structure investigation that was critical to the project.

Final drawings are sent to the governmental office to obtain a building permit and to the owner to make a contract. The structural database is transformed into the format for the estimation systems in the construction department. At the same time, the structural database is transformed into the format for the work-drawing CAD systems. This automatic transformation has drastically reduced the time for drawing.

\subsubsection{Diffusion of IT Funding}

Since analyzing the diffusion of IT funding requires detailed financial data for a company, it is, in most cases, difficult to open data in public for reasons of confidentiality. Therefore, the following analysis is based on the data obtained only from Kajima's annual reports and materials for the general meeting of stockholders. Due to the lack of data, the analysis includes many assumptions.

Table 3.3 shows Kajima's investment in R\&D and plant and equipment. The percentage of Investment in R\&D among the total revenue is constant, compared to that in plant and equipment. This indicates that Kajima's investment in $R \& D$ heavily depends on its total revenue.

The upper graph in Figure 3.15 illustrates the investment in R\&D. Since this investment in $R \& D$ is the major financial source of the LINCS project and other IT-related projects, it is appropriate to assume that Kajima's investments in IT follows the same shape as the investments in R\&D. The lower graph in Figure 3.15 shows the assumed distribution of investments in IT. Extracting the expenses of IT from the total investment is difficult, 
however, considering the fact that investments in IT in Japanese companies hold approximately $15 \%$ of their total investments in plant and equipment compared to $40 \%$ in American companies (Moriyama, 2000), it is roughly in the order of trillions of yen.

The proportions of each stage are assumed by the results obtained from Figure 3.11. These proportions indicate that Kajima's investment in IT increased rapidly during its substitution stage. During this period, Kajima established an intra-network called KI (Kajima Intelligent) Net and purchased PCs for almost all the employees. Although it is absolutely true that the so-called Bubble Economy in Japan during the early 90 's greatly affected the surge of investments, Kajima may have made the best use of the boom to improve IT infrastructure for the next diffusion steps.

In terms of the enhancement and the transformation stages in the IT diffusion, these stages began almost at the same time when the LINCS project started, causing the overlap of funding of two stages. In the case of the LINCS project, classifying the investments between these stages is difficult or rather meaningless. The more important fact is that the total amount of IT funding began to reduce when the LINCS project started.

\section{Table 3.2 Kajima's Investments in R\&D and Plant and Equipment (Kajima Annual Report, 1998)}

\begin{tabular}{|c|c|c|c|c|}
\hline Fiscal Year & $\begin{array}{l}\text { Investment } \\
\text { in R\&D } \\
\text { (Millions of Yen) }\end{array}$ & $\begin{array}{c}\text { Percentage in } \\
\text { total revenue } \\
(\%)\end{array}$ & $\begin{array}{c}\text { Investment } \\
\text { in plant \& equipment } \\
\text { (Millions of Yen) }\end{array}$ & $\begin{array}{c}\text { Percentage in } \\
\text { total revenue } \\
(\%)\end{array}$ \\
\hline 1988 & 11,057 & $(0.89)$ & --- & --- \\
\hline 1989 & 14,648 & $(1.03)$ & --- & --- \\
\hline 1990 & 19,142 & (1.13) & --- & --- \\
\hline 1991 & 23,152 & (1.19) & --- & --- \\
\hline 1992 & 25,205 & $(1.29)$ & --- & --- \\
\hline 1993 & 25,280 & $(1.44)$ & --- & --- \\
\hline 1994 & 24,834 & (1.38) & --- & -- \\
\hline 1995 & 22,882 & (1.57) & 13,055 & $(0.90)$ \\
\hline 1996 & 22,063 & (1.37) & 17,873 & $(1.11)$ \\
\hline 1997 & 20,235 & (1.34) & 20,541 & $(1.36)$ \\
\hline 1998 & 17,751 & (1.42) & 8,782 & $(0.70)$ \\
\hline *1999 & 16,000 & (1.33) & 6,000 & $(0.50)$ \\
\hline
\end{tabular}




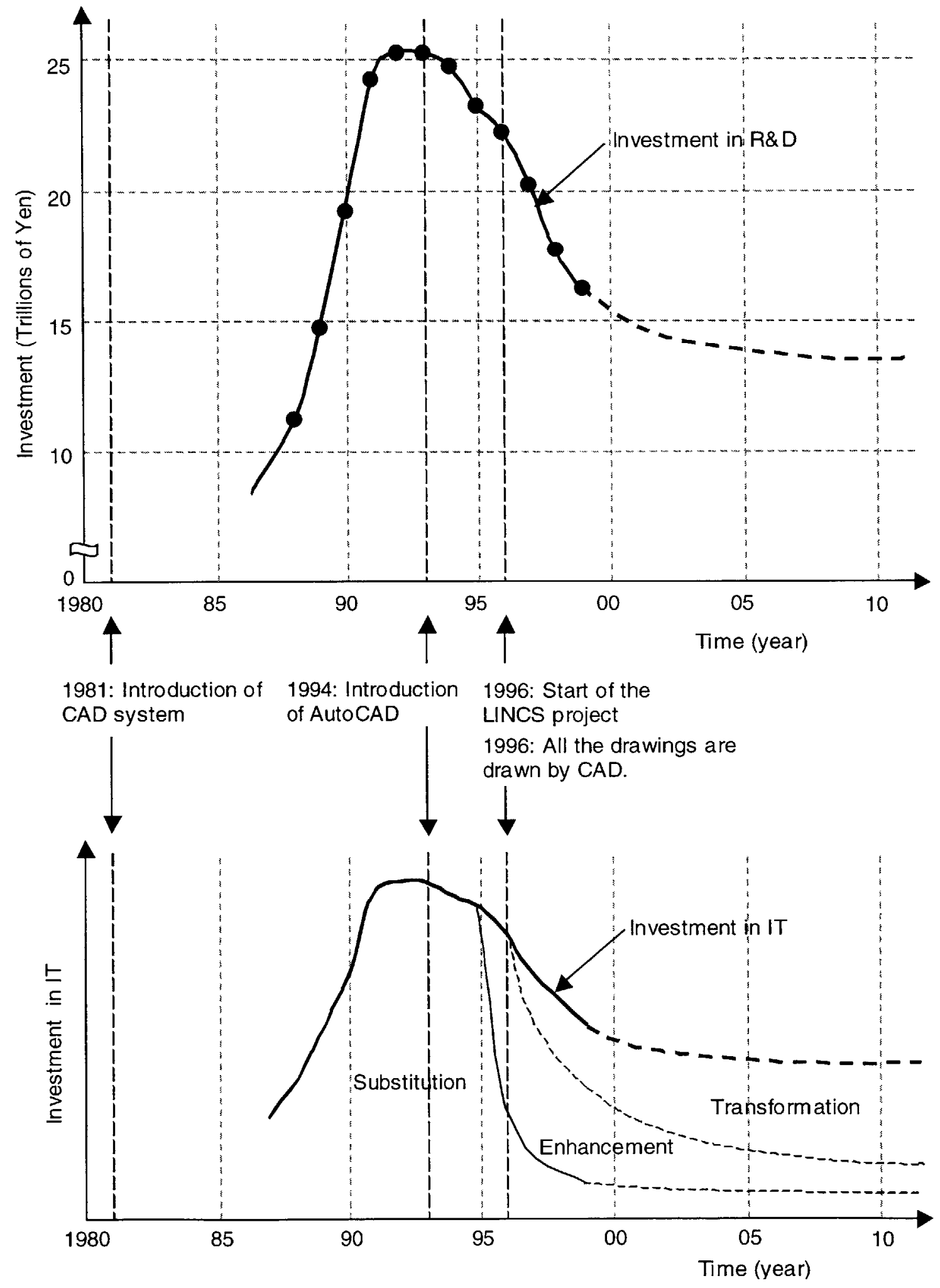

Figure 3.15 Diffusion of IT Funding in Kajima 


\subsubsection{IT Diffusion Modeling}

In terms of IT modeling, Weber (1997) has adopted a highly simplified, though plausible model of IT diffusion based on logical growth. Causal loop diagrams are basic system dynamics tools, which provide a method of capturing the multiple cause-effect relationships that the experts use to understand the complexity of their part of the system and its relationship with the rest of the system. In mapping out expert mental models, causal loop diagrams also provide a method for integrating multiple expert mental models into a single, all-encompassing model of the system (Morecorft and Sterman, 1994).

Although this causal loop diagram provides a good understanding of causal relationship, it is generally not appropriate for simulation or optimization purposes, since it does not include quantitative elements or the concept of time. We need to add state valuables as stocks and their time-derivatives as flows to visualize the dynamic mechanism of the IT diffusion. Following this idea, in this case study, I augmented Weber's model and created the system dynamics model for IT diffusion (Figure 3.16), which shows a simplified model of IT diffusion at the level of a company. The valuables included in this model are selected from the outputs (investments) and inputs (benefits) model of an IT program discussed in the next section (Figure 3.17).

The model is driven by expenditure in IT, which results in the increase of the demand of IT. In the presence of a more sophisticated IT infrastructure, i.e., hardware and software, the demand for IT is expected to rise, which then increases the "level of informatization"; the percentage of workflow that is informatized.

The diffusion of IT is modeled here in terms of "penetration-percentage", the percentage of activities that can be regarded as fully enhanced through the use of IT. More specifically, the diffusion can be understood as the fraction of job-hours spent while working on integrated information systems. The modeling of IT diffusion is particularly important during the start-up phase of new information systems. 


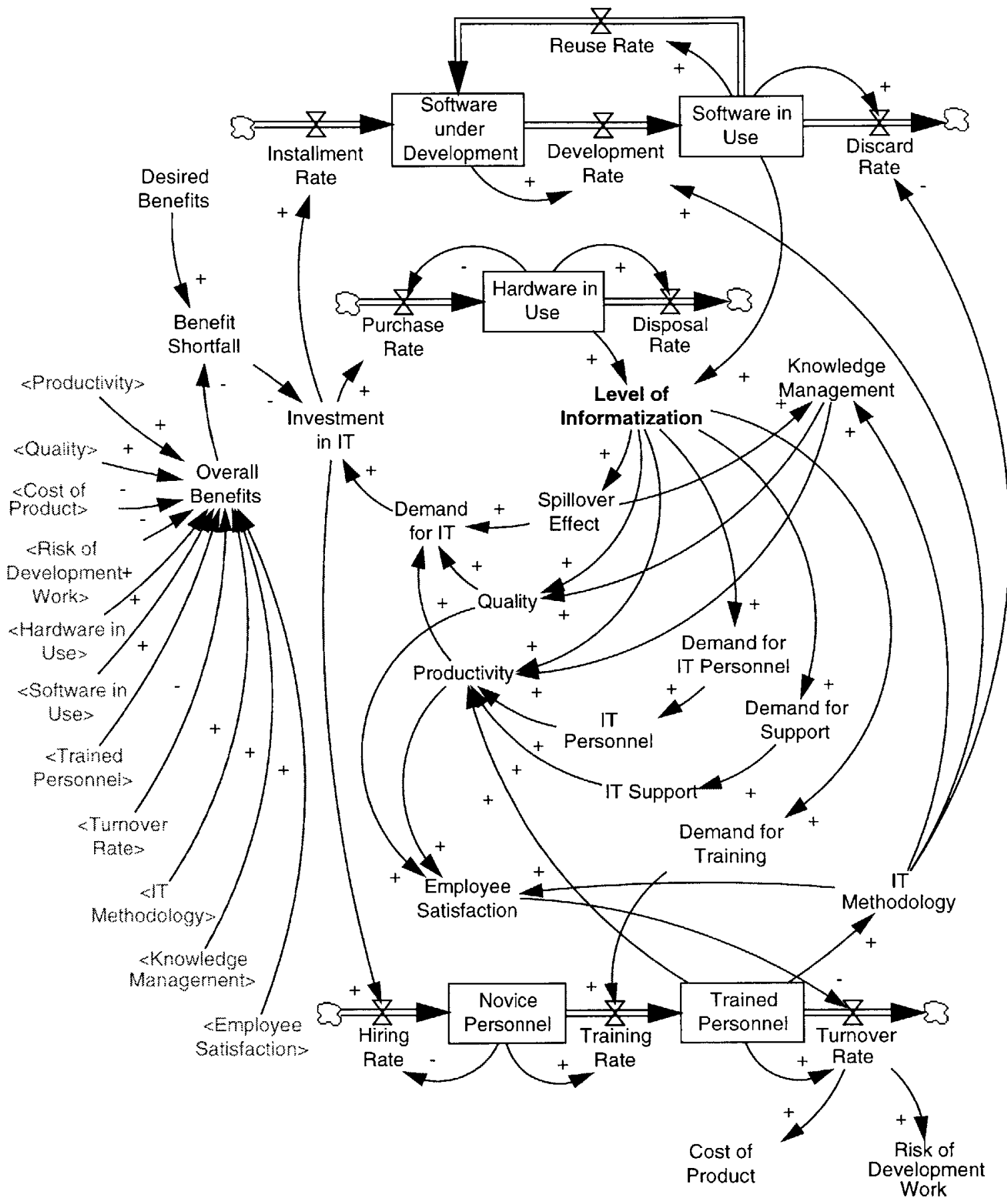

Figure 3.16 System Dynamics Model for IT Diffusion (augmented from Weber, 1997) 


\subsection{IT Investment Modeling}

This section presents the last step of the IT planning framework: IT investment modeling. In this case study, I first identify the business value of the LINCS system, and second, evaluate the validity of Kajima's investment in the LINCS project by executing the costbenefit analysis.

\subsubsection{Assessing the Business Value of IT}

This section presents the method to assess the business value of IT in the entire valueadding workflow in Kajima. In this case study, I adopted the process-oriented framework proposed by Mooney, et al. (1996).

\subsubsection{A Process-Oriented Framework}

It is commonly held that the business value of IT is closely tied to an organization's business strategy (Parker and Benson, 1988). However, IT in itself cannot be held responsible for the ultimate success or failure of the business strategy. By adopting a process perspective of IT impacts, we can examine the impacts of IT on successful and unsuccessful processes rather than on firms, thus broadening and balancing the sample space, and again contributing to an improved understanding of IT impact.

Therefore, we see the need for a process view of IT organization interactions for the following reasons: (1) to identify the value-adding mechanism of IT; (2) to develop an approach and set of metrics for measuring the technology's business value; and (3) to enhance our understanding of the relationship between IT and organizations. Our belief is that firms derive business value from IT through is impacts in intermediate business

processes. Business processes are comprised of the range of operational processes that comprise a firm's value chain and the management processes of information processing 
control, coordination, communication, and knowledge. The approach to studying IT business value proposed here is thus through a focus on the fundamental ways by which the technology can improve management and operational processes.

Mooney et al. (1996) proposed that IT has three separate but complementary effects on business processes. Further, it is though these effects on business processes that IT creates value. First, automational effects refer to the efficiency perspective of value deriving from the role of IT as a capital asset being substituted for labor. Within this dimension, value drives primarily from impacts such as productivity improvements, labor savings, and cost reductions. Second, information effects emerge primarily form IT's capacity to collect, store, process, and disseminate information. Following these effects, value accrues from improved decision quality, employee empowerment, decreased use of resources, enhanced organizational effectiveness, and better quality. Third, transformational effects refer to the value deriving from IT's ability to facilitate and support process innovation and transformation. The business value associated with these effects will be manifested as reduced cycle times, improved responsiveness, downsizing, and service and product enhancement as a result of reengineered processes and redesigned organizational structures.

\subsubsection{Process-Oriented IT Business Value Matrix}

To quantify the costs and benefits of information technology of an IT project, a statistical approach such as the one by Hitt and Brynfolfsson (1996) is not appropriate. Mooney et al. (1996) suggested a process-oriented approach for assessing the business value of IT that takes place both at the managerial and the operational level. According to Mooney et al., IT encompasses "automational", "informational", and "transformational" dimensions, which stand in contrast to firm-level output measures. Table 3.4 shows the process-oriented IT value matrix. It is clear that the IT value dimensions shown in Table 3.4 are related to the different diffusion phases. Namely, automational value will play a role mostly in the early stages of diffusion, substitution and enhancement. On the contrary, in the latter stage, the transformational value of IT is likely to become dominant. 
Table 3.4 Process-oriented IT Business Value Matrix (adapted from Mooney et al., 1996)

\begin{tabular}{|c|c|c|c|c|}
\hline & & \multicolumn{3}{|c|}{ Dimensions of IT Business Value for Kajima } \\
\hline & & Automational & Informational & Transformational \\
\hline \multirow{3}{*}{ 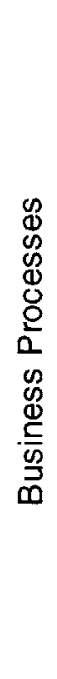 } & 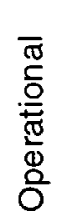 & $\begin{array}{l}\text { - Labor cost } \\
\text { - Reliability } \\
\text { - Efficiency } \\
\text { - Inventory costs }\end{array}$ & $\begin{array}{l}\text { - Utilization } \\
\text { - Wastage } \\
\text { - Operational flexibility } \\
\text { - Quality }\end{array}$ & $\begin{array}{l}\text { - Product and service } \\
\text { innovation } \\
\text { - Cycle times } \\
\text { - Customer relationships }\end{array}$ \\
\hline & 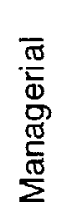 & $\begin{array}{l}\text { - Administrative expense } \\
\text { Control } \\
\text { - Reporting } \\
\text { - Routinization }\end{array}$ & $\begin{array}{l}\text { - Effectiveness } \\
\text { - Decision quality } \\
\text { - Resource usage } \\
\text { - Empowerment } \\
\text { - Creativity }\end{array}$ & $\begin{array}{l}\text { - Competitive flexibility } \\
\text { - Competitive capability } \\
\text { - Organizational form }\end{array}$ \\
\hline & 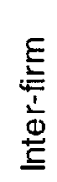 & - Transaction cost & - Search cost & - Collaborative design \\
\hline
\end{tabular}

\subsubsection{Cost Benefit Analysis}

The last task of the IT investment modeling is to perform cost-benefit analysis. The costbenefit analysis exposes the value-creating mechanism in a firm and evaluates the validity of investments in a project. The steps of this analysis are: classification of investments and benefits, allocation of investments and benefits, and evaluation of the validity of investments.

\subsubsection{Classification of Investments and Benefits}

Before performing cost-benefit analysis, it is important to classify investments and benefits. Figure 3.17 provides a diagram of inputs (investments) and outputs (benefits or losses) of an IT program (process). These classifications are also useful in the evaluation step if benefits resulting from the IT program can be systematically categorized. 


\section{$\underline{\text { Investments }}$}

Investments are divided into two categories: initial investments and enabling investments. Initial investments are made in the form of hardware, software, and personnel, which are fundamental and indispensable elements in starting an IT program. The personnel in this category include inexperienced employees who will become the users of IT and, at most, semi-trained professionals who could be part of the support or administration staff.

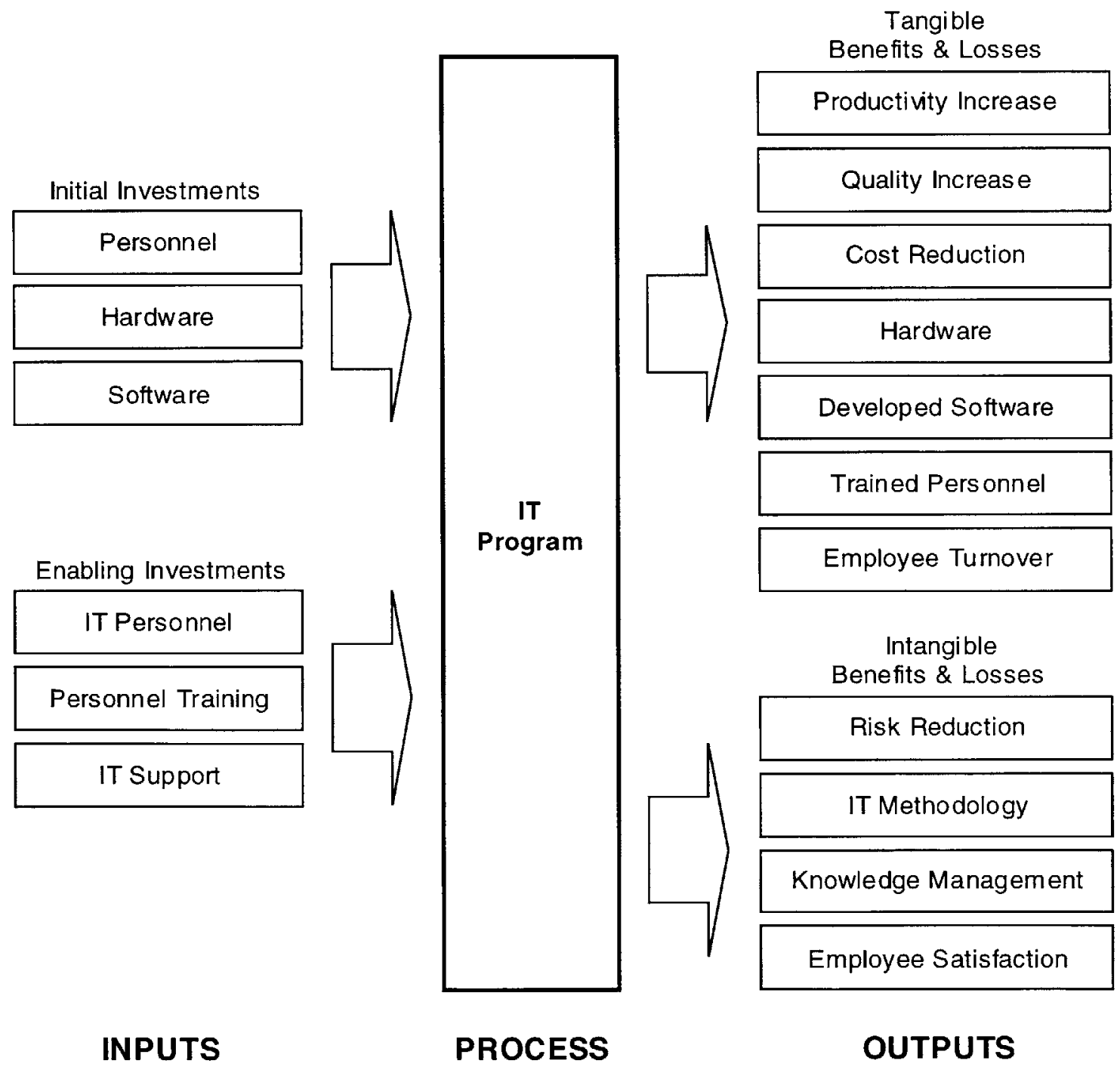

Figure 3.17 IT Program Inputs and Outputs (adapted from Peña-Mora et al., 1999) 
On the other hand, enabling investments are composed of IT personnel, personnel training, and IT support. Their primal duty is to draw out the potential abilities of the initial investments. IT personnel include trained experts to take the lead in the implementation and expert consultants to assist and guide the implementation. Along with the personnel in the initial investment category, the composition of the project member influences the personnel training and IT support investments and the success of the IT program.

It is important to mention here that the nature of these investments will vary over the life of the IT program, as it proceeds through the different phases of the IT diffusion. Depending on the complexity and uniqueness of an implementation, these categories will carry differing weights, both in terms of impact and in terms of investment. For example, a unique IT implementation may require a great deal of development, whereas a complex but standard implementation would require a comparatively higher investment in standardized hardware.

\section{$\underline{\text { Benefits }}$}

Benefits of an IT program are classified into two categories: tangible and intangible benefits and losses. The tangible benefits and losses occur in the form of productivity increase, quality increase, cost reduction, hardware, developed software, trained personnel and employee turnover. Productivity and quality increase and cost reduction are felt throughout the development and deployment phases of a project but not all the project participants receive these benefits. Hardware, developed software, and trained personnel accumulated through the entire project and are shared by all the project participants at the end of a project. IT investment occasionally results in negative returns especially during the deployment phase of a project. The loss of trained employees represents a loss in the overall expertise in a company. In the field of information technology, this expertise is an extremely important asset.

The intangible benefits are in the form of risk reduction, IT methodology, knowledge 
management, and employee satisfaction. Risk reduction, along with productivity increase and quality increase, is the primary return from an IT investment (Venkatraman, 1997) and its effect is also felt throughout all the processes of a project. IT methodology means the collection of technique accumulates mainly during the development phase of a project and is shared among the organization participants. Knowledge management is know-how that manages the IT methodology obtained through the processes of a project. The quality of products and productivity affects employee satisfaction. Since these benefits reduce the rate of employee turnover, companies must contrive to keep the employees' satisfaction level high.

\subsubsection{Allocation of Investments}

The next step in the cost-benefit analysis is to detect the recipients of investments. This

process, along with the allocation of benefits, is important in order to evaluate the effect of investments. Table 3.5 shows the investment allocation of the LINCS project. The sources of investments are the same as the participants of the LINCS project: structural engineering section in $\mathrm{A} / \mathrm{E}$, technical support section in Construction, and the IT support section in the Tokyo Branch. In addition, since the LINCS project is treated as one of Kajima's principal projects, the head office invests a substantial amount of money from its budget for research and development. Following the manner in the previous section, I classify investments in the LINCS project into personnel, hardware, software, IT personnel, personnel training, and IT support. Table 3.5 clearly shows that investments to LINCS are heavily concentrated in the $\mathrm{A} / \mathrm{E}$ department. Compared with the investments to $\mathrm{A} / \mathrm{E}$, investments to Construction are light.

\section{$\underline{\text { Personnel }}$}

In terms of personnel, $\mathrm{A} / \mathrm{E}$ organized a DBCAD team, consisting of four structural engineers and several drawing persons, in the structural engineering section. The team not only develops $\mathrm{DBCAD}$, but also implements $\mathrm{DBCAD}$ to actual construction projects. In each project, the team manages the design schedule, assists the operation of DBCAD 
mainly to create structural databases, and controls the exchange of the database with architects and mechanical engineers.

Table 3.5 Investment Allocation of LINCS

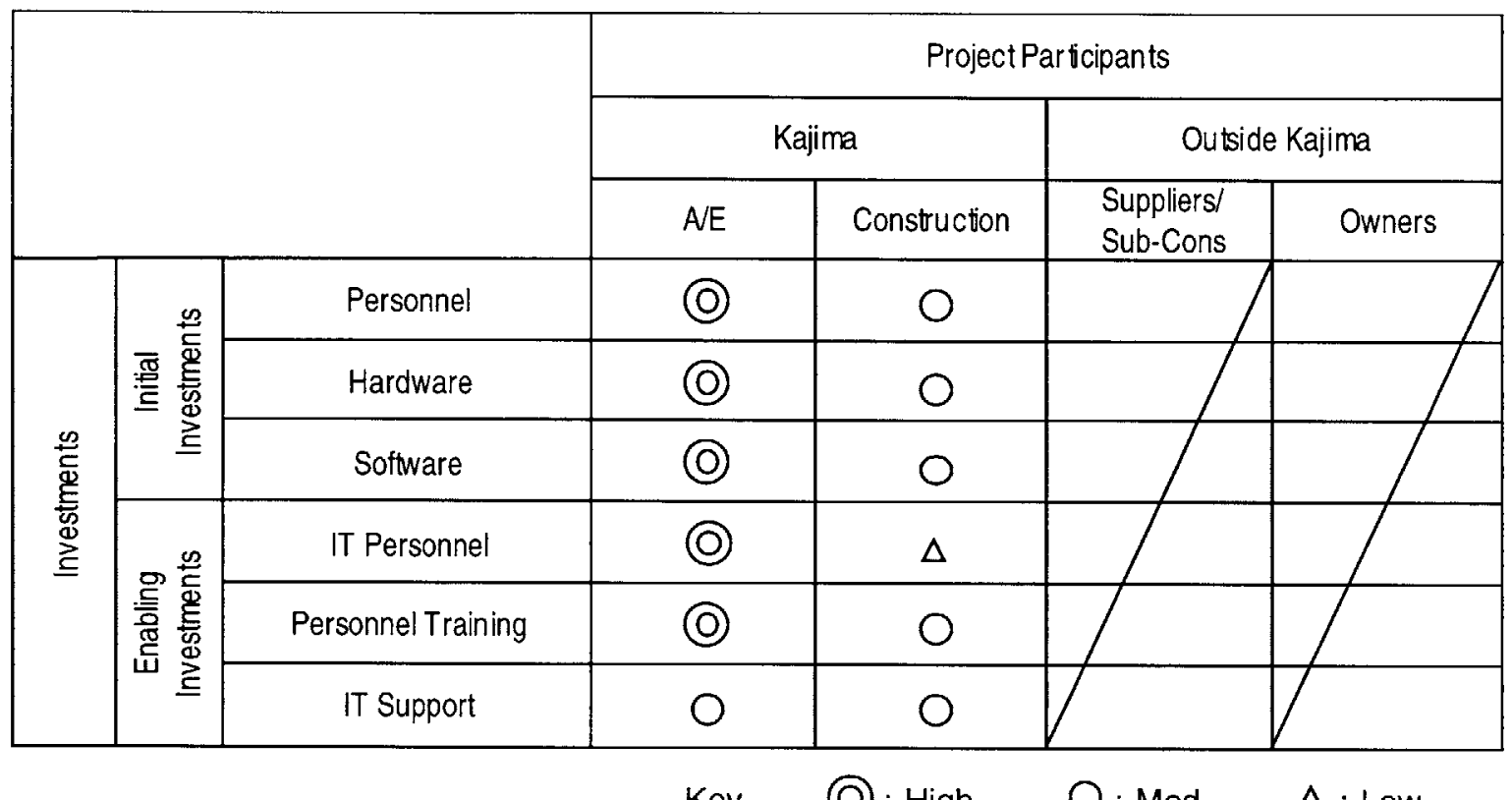

Key (O): High $\bigcirc$ : Med $\Delta$ : Low

\section{$\underline{\text { Hardware and Software }}$}

In terms of hardware and software, investments had already started before the LINCS project started. At the same time of the introduction of AutoCAD in 1994, A/E placed PCs for every architect and engineer in the department. In addition, plotters for large sheet drawing were installed. When the LINCS project started in 1996, A/E purchased new PCs to be able to meet the requirements of DBCAD. Investment in software went mainly to the development of DBCAD. Although $\mathrm{A} / \mathrm{E}$ planned the basic concept and the structure of DBCAD, it outsourced the programming work of DBCAD.

In Construction, in terms of hardware, several PCs with CAD software, an MO disk drive, and a plotter were placed in each construction site to create construction drawings. In terms of software, to transform the structural database to data formats for construction supporting 
applications, such as steel-frame $\mathrm{CAD}$, reinforcing-bar $\mathrm{CAD}$ and estimation systems, several simple programs were developed in the construction preparation stage.

\section{Training}

In terms of training, the $\mathrm{DBCAD}$ team also provides the training course for $\mathrm{DBCAD}$ as well as for the normal CAD applications. The training course covers everything from the basic operation of CAD software to the operation of customized function of CAD and the process of creating the structural databases. The training course is mandatory for every structural engineer; however, the length of the course varies from one day to one week, depending on the title of the engineers (shorter for senior engineers and longer for junior engineers). In terms of support, the DBCAD committee, organized by the LINCS members, monitors and controls the whole LINCS project.

\subsubsection{3. $\quad$ Allocation of Benefits}

The last step of cost-benefit analysis is to allocate the benefits. Table 3.6 shows the allocation of benefits of the LINCS project. The recipients of benefits include not only the participants of the LINCS project, but also other companies outside Kajima such as subcontractors, suppliers, and clients. It is important to notice here that productivity increase, quality increase, and risk reduction are immediate returns and they bring about primary benefits to the clients and operators of the project.

\section{Productivity and Quality}

Despite many of the known and well-accepted benefits of IT such as reduction in transaction and search cost, as well as increase in efficiency of operations, actual increases

of productivity and quality are hard to detect. However, I try to evaluate them from the information obtained from the interviews with several employees in Kajima. 
Table 3.6 Benefit Allocation of LINCS

\begin{tabular}{|c|c|c|c|c|c|c|}
\hline & & & \multicolumn{4}{|c|}{ Project Participants } \\
\hline & & & \multicolumn{2}{|c|}{ Kajima } & \multicolumn{2}{|c|}{ Outside Kajima } \\
\hline & & & AVE & Construction & $\begin{array}{l}\text { Suppliers/ } \\
\text { Sub-Cons } \\
\end{array}$ & Owners \\
\hline \multirow{11}{*}{ 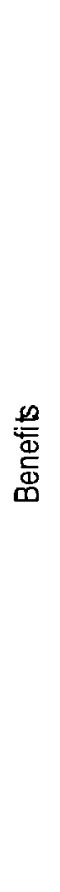 } & \multirow{7}{*}{ 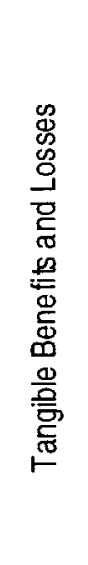 } & Productivity Increase & 0 & (O) & 0 & $\Delta$ \\
\hline & & Quality Increase & 0 & (2) & 0 & 0 \\
\hline & & CostReduction & $\Delta$ & (O) & $\Delta$ & (O) \\
\hline & & Hardware & 0 & 0 & $\Delta$ & $\Delta$ \\
\hline & & Developed Software & (O) & 0 & $\Delta$ & $\Delta$ \\
\hline & & Trained Personnel & (O) & 0 & $\Delta$ & $\Delta$ \\
\hline & & Employee Turnover & $\Delta$ & $\Delta$ & $\Delta$ & $N / A$ \\
\hline & \multirow{4}{*}{ 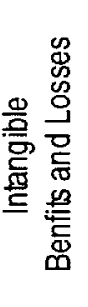 } & Risk Reduction & $\Delta$ & (O) & $\Delta$ & $\Delta$ \\
\hline & & IT Methodology & (O) & 0 & $\Delta$ & $\Delta$ \\
\hline & & Knowledge Management & (O) & 0 & $\Delta$ & $\Delta$ \\
\hline & & Employee Satisfaction & 0 & 0 & $\Delta$ & $N / A$ \\
\hline
\end{tabular}

The interviewees were employees who are in charge of the drawing work. Their most striking consensus was that the time spent to create a drawing by using DBCAD had not been reduced compared to the time spent by using the conventional CAD applications. Most of them pointed out that DBCAD is still an unfriendly and inflexible to operate. Plans, sections, and member lists are automatically produced from the structural database, however, these drawings need modifications or more information by using conventional $\mathrm{CAD}$, such as adding hole positions for mechanical pipes and comments. Interviewees also claimed that the time spent on these modifying tasks is not negligible. In addition, DBCAD applies only to regular-shaped buildings, such as warehouses or apartment houses. When a building is irregularly shaped, round, or triangular, inputting the building grid is a 
painstaking work. From these interviews, I conclude that the productivity and quality has not been improved by the introduction of LINCS in the design stage. In contrast, in the construction stage, owing to the shortening of the drawing period for the site drawings, productivity has been dramatically increased.

\section{$\underline{\text { Cost reduction }}$}

Increased quality and productivity accomplished by using the LINCS system resulted in the cost reduction mainly in the construction stage. This reduction of cost reflected the cost of final products (buildings). Therefore, the Construction department and the client of the construction project received the benefits of cost reduction.

\section{Developed Software}

The developed DBCAD system is one of the most valuable benefits of the LINCS project, especially to the $\mathrm{A} / \mathrm{E}$ department because $\mathrm{DBCAD}$ system is technically applicable to any type of buildings. Although DBCAD still has much room for improvement, its potential is very high. The Construction department develops some simple software for data transformation; however, its functions are limited and therefore its value is trivial.

\section{Trained personnel}

Trained personnel are one of the most important benefits in the area of information technology. In $\mathrm{A} / \mathrm{E}$, employees accumulate operation techniques through the use of $\mathrm{DBCAD}$ and it increases the productivity of the design work. In construction sites to which the LINCS system is applied, employees who are in charge of CAD operations, usually young site managers, obtain IT-related skill that is utilized as expertise at the next construction site.

\section{Employee Turnover}

Historically, employee turnover has not been a big issue in Japan. In Japanese construction 
companies, like many of the other companies in Japan, lifetime employment is considered to be the standard style. Since a young professional enters a company after graduation, the company makes a long-term commitment to the training and professional growth of the employee, hoping the employee will a real asset to the company. In return, employees exhibit a high level of loyalty to the company and its managers. This tendency seems to be more apparent in the construction industry. While most of the Japanese manufacturing and financial companies dismissed many employees during the depression followed by the Bubble Economy, large-scale general contractors including Kajima did not choose the dismissal formula as a means to survive their financial difficulties.

\section{$\underline{\text { IT methodology and Knowledge Management }}$}

IT methodology arises from the accumulated ideas about efficient ways to develop and execute IT projects. It even includes miscellaneous information, such as comments and claims from the users of an IT system. Knowledge management is a technique to manage the IT methodology. It is difficult to substantiate or quantify these two benefits; however, all the project participants accumulate them over the duration of the project and utilize them in their actual jobs, unconsciously.

\section{Employee satisfaction}

Increased productivity and quality though the use of LINCS brings employees a feeling of satisfaction. This feeling results in the decrease of turnover rate.

\subsubsection{Evaluation of Investments}

Table 3.7 combines Table 3.5 and Table 3.6. It summarizes the investment and benefit allocation of LINCS mentioned in this section. This result indicates the inequality in the distribution of benefits among the participants of the LINCS project. Namely, the majority of investments in the LINCS project go to $\mathrm{A} / \mathrm{E}$ and Construction; however, benefits go mainly to Construction and outside of Kajima organization, such as suppliers and sub- 
contractors. Considering this unbalanced distribution of costs and benefits, senior management has to reasonably evaluate each organization's achievements and rearrange the investment strategy.

Table 3.7 Inequality in Investment and Benefit Allocation of LINCS

\begin{tabular}{|c|c|c|c|c|c|c|}
\hline & & & \multicolumn{4}{|c|}{ Project Participants } \\
\hline & & & \multicolumn{2}{|c|}{ Kajima } & \multicolumn{2}{|c|}{ Outside Kajima } \\
\hline & & & $A / E$ & Construction & $\begin{array}{l}\text { Suppliers/ } \\
\text { Sub-Cons }\end{array}$ & Owners \\
\hline \multirow{6}{*}{ 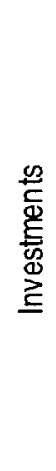 } & \multirow{3}{*}{ 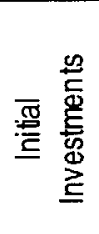 } & Personnel & (O) & 0 & & \\
\hline & & Hardware & () & 0 & & \\
\hline & & Software & (Q) & 0 & & \\
\hline & \multirow{3}{*}{ 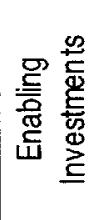 } & IT Personnel & (C) & $\triangle$ & & \\
\hline & & Personnel Training & (Q) & & & \\
\hline & & IT Support & & & & \\
\hline \multirow{11}{*}{ 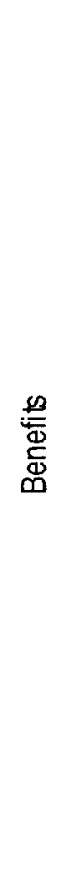 } & \multirow{7}{*}{ 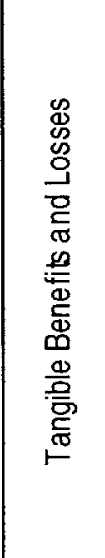 } & Productivity Increase & 0 & & 8 & $\triangle$ \\
\hline & & Quality Increase & 0 & (O) & 0 & C \\
\hline & & CostReduction & $\Delta$ & (a) & $\Delta$ & (Q) \\
\hline & & Hardware & 0 & & $\triangle$ & $\triangle$ \\
\hline & & Developed Software & (O) & $\Delta$ & $\Delta$ & $\Delta$ \\
\hline & & Trained Personnel & (2) & 0 & $\Delta$ & $\Delta$ \\
\hline & & Employee Turnover & $\Delta$ & $\Delta$ & $\Delta$ & N/A \\
\hline & \multirow{4}{*}{ 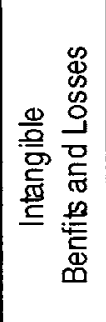 } & Risk Reduction & $\Delta$ & (a) & $\Delta$ & $\Delta$ \\
\hline & & IT Methodology & (0) & 0 & $\Delta$ & $\Delta$ \\
\hline & & Knowledge Management & (O) & $\bigcirc$ & $\Delta$ & $\Delta$ \\
\hline & & Employee Satisfaction & 0 & 0 & $\Delta$ & $\mathrm{N} / \mathrm{A}$ \\
\hline
\end{tabular}




\section{Chapter 4. Conclusion}

New IT developments continue to have a significant impact on general contractors in Japan. To maximize returns on their IT investments, the senior management of general contractors faces a number of difficult questions:

- How should IT investments be designed to ensure alignment with overall project objectives and strategy?

- How should these investments be justified?

- How can the value of these IT investments be measured over the project life span?

- How can the value of IT investments be quantified when the benefits accrue to more than one participating party?

To answer these questions, Peña-Mora and Weber proposed an IT strategic planning framework for construction companies. The framework has four distinct phases: (1) environmental scan, (2) internal scrutiny, (3) IT diffusion analysis, and (4) IT investment modeling. This framework takes account of the fact that the construction industry has come to the point where it must embrace information technology on a fundamental level. To examine the validity of the IT planning framework, this thesis presents a case study of an IT project, called the LINCS project, which is being developed by the Kajima Corporation, one of the largest general contractors in Japan. 
In the environmental scan step, the characteristics of the Japanese construction industry were first analyzed and it was observed that the IT problems common in the West were rarely experienced by the Japanese construction industry. Second, Japanese general contractors were analyzed and the analysis showed that Japanese general contractors, especially large-scale firms, are highly vertically integrated, performing most of the stages of the value chain in the construction industry. Third, the analysis of the economic environment of the Japanese general contractors concluded that Bubble Economy consequently provided general contractors an opportunity to maintain and improve their infrastructures.

In the internal scrutiny step, the Kajima Corporation and the LINCS project were analyzed. The analysis shows that Kajima's organization is highly vertically integrated, the same as the other large-scale Japanese general contractors. The analysis also shows the role of each organization in the whole workflow of a construction project. The analysis of the information flow in Kajima reveals that LINCS is expected to solve the communication inefficiencies between different organizations.

IT diffusion analysis concludes that the LINCS project has just entered the transformation stage of the IT diffusion through the following processes: first, IT applications, such as $\mathrm{CAD}$ and structural analysis systems, have been substituted for conventional manual labor. Next, by doing design and drawing work concurrently, DBCAD enhances the structural design processes. Finally, by sharing the Structural database among all the participants in a construction project, the design and construction work have been synthesized and transformed into a more efficient system.

IT diffusion analysis also revealed the weakness of LINCS:

- DBCAD currently applies only to regular-shaped buildings.

- The structural database is not linked with the architectural/mechanical design database. 
Kajima is now struggling to develop an architectural DBCAD and mechanical DBCAD, but the integration of the three DBCAD systems has not yet started.

- The management system of drawings in Japan is complex and inefficient compared to that of the West. This is one of the difficulties in implementing IT in the Japanese construction industry.

IT investment modeling reveals the inequality in the distribution of benefits among the participants of the LINCS project. Namely, while the majority of the investments in the LINCS project go to $\mathrm{A} / \mathrm{E}$ and Construction, the benefits mainly go to Construction and other companies outside Kajima, such as suppliers and sub-contractors. In consideration of these imbalances of the cost-benefit relationship, senior management has to evaluate each organization and rearrange the investment structures.

Last, this research verifies that, by including both design and construction functions, Japanese general contractors have a desirable organizational structure for implementing IT in the construction industry. In the case of the LINCS project, the Construction division receives the benefits of IT investments in the $\mathrm{A} / \mathrm{E}$ division - two different organizations in one entity, the Kajima Corporation. This ingenious mechanism cannot function in Western construction companies, where the construction market domain is highly fragmented and a company rarely performs both design and construction work. Taking full advantage of an "IT-friendly" organization and of the high technology they already possess, Japanese general contractors have a fair potential to take the initiative in revolutionizing the entire construction system. 


\section{References}

ASCE (1992). Design-Build in the Federal Sector, ASCE, Washington.

Bensaou, M., and Earl, M. (1998). "The Right Mind-set for Managing Information Technology", Harvard Business Review, 1998, September-October, 119-128.

Betts, M., Cher, L., Mathur, K., and Ofori, G. (1991). "Strategies for the construction sector in the information technology era." Construction Management and Economics, U.K., 9, 509-528.

Bjork, B., (1985). Computers in Construction; Research, Development and Standardization Work in the Nordic Countries, Technical Research Center of Finland.

Brochner, J., (1990). "Impacts of Information Technology on the Structure of Construction." Construction Management and Economics, 1990, 8, 205-218.

Brynjolfsson, E., and Hitt, L. (1996). "Paradox Lost? Firm-Level Evidence on the Returns to Information Systems Spending." Management Science, Vol. 42, No. 4, pp. 541558 .

Friedlander, M. C., (1998). "Design/Build Solutions." Journal of Management in Engineering, November/December, 1998, 59-64.

Fredrickson, K. (1998). "Design Guidelines for Design-Build Projects." Journal of Management in Engineering, January/February, 1998, 77-80.

Hannah, N., Guy, K., and Arnold, E. (1995). "The Diffusion of Information Technology: Experience of Industrial Countries and Lessons for Developing Countries." World Bank Discussion Papers, No. 281, Washington D.C.

Hasegawa, F., and Shimizu Group FS (1988). Built by Japan: Competitive strategies of the Japanese construction industry, John Wiley \& Sons. New York.

Kajima Corporation (1998). Kajima Annual Report 1998.

Kajima Corporation (1997). Kajima Corporation Brochure.

Kajima Corporation (1994). Kajima Information Processing Center Brochure.

Kajima Corporation (1998). Kajima Internal Report. 
Kajima Corporation (2000). Personal Interview with Kajima Employees.

Kanemoto, Y. (1999). Nihon no Kensetsu Sangyo (Japanese Construction Industry), Nihon Keizai Shinbun-sya, Tokyo.

Kennedy, J. F. (1997). "Computer Supported Negotiation and Dispute Resolution in the Large Scale Civil Engineering and Construction Domain", M.S. Thesis, Massachusetts Institute of Technology, Cambridge, Massachusetts.

Mooney, J.G. and Gurbaxani, V., and Kraemer, K.L. (1996). "A Process-Oriented Framework for Accessing the Business Value of Information Technology." The Database for Advances in Information Technology, Vol. 27, No. 2, pp. 68-78.

Morecroft, J. D. W., and Sterman, J., D., eds. (1994). Modeling for Learning Organizations. Productivity Press, Portland, Oregon.

Moriyama, M. (2000). Nihon Keizai Shinbun, January 24.

Parker, M. J., and Benson, R. J. (1988). Information Economics: Linking Business Performance to Information Technology, Englewood Cliffs, NJ: Prentice-Hall.

Peña-Mora, F., Vadhavkar, S., Perkins, E., and Weber, T. (1999). "Information Technology Planning Framework for Large-Scale Projects." Journal of Computing in Civil Engineering, October, pp. 226-237.

Porter, M. E. (1985). Competitive Advantage, Free Press, New York.

Sakai, H., and Yamane, F. (2000). Personal Interview with Kajima Employees.

Tozer, E. E. (1996), Strategic IS/IT Planning, Butterworth Heinemann, Massachusetts.

Venkatraman, N. (1997). "Beyond Outsourcing: Managing IT Resources as a Value Center", Sloan Management Review, Spring, pp. 51-64.

Weber, T. A., (1997). "Constrained Predictive Control for Corporate Policy." M.S. Thesis, Massachusetts Institute of Technology, Cambridge, Massachusetts.

Weber, T. A., and Peña-Mora, F. (1997). "Information Technology Strategy in the Providence of Mendoza: Case Studies and Modeling Framework." IESL Report 97, Intelligent Engineering Systems Laboratory, Massachusetts Institute of Technology, Cambridge, Massachusetts. 